Meteorol. Atmos. Phys. 48, 51-75 (1992)

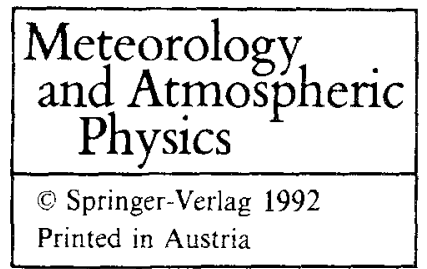

551.515 .1

DLR, Institut für Physik der Atmosphäre, Oberpfaffenhofen, Federal Republic of Germany

\title{
Fronts and the Alps: Findings from the Front Experiment 1987
}

\author{
K. P. Hoinka and H. Volkert
}

With 22 Figures

Received October 11, 1991

Revised January 15, 1992

\begin{abstract}
Summary
The "German Front Experiment 1987" was an experimental effort to determine the influence of the European Alps on cold fronts using data collected by aircraft, radar, surface and upper-air systems between October and December 1987. Measurements were concentrated in the Alpine foreland south of Munich and in the Inn valley in Austria. It was a cooperative effort by groups from Austria, Germany and Switzerland. This study briefly recapitulates the conduct of the experiment and the intense observation periods which were carricd through. Then it is outlined to what extent the scientific objectives have been achieved. The findings of the experiments are grouped into the following topics: orographically induced frontogenesis, the interaction of foehn and front, orographically trapped gravity currents, flow into valleys and the modification of precipitation by the Alps.
\end{abstract}

\section{Introduction}

During summer 1918 a series of coordinated surface- and ship-based measurements was performed at the Norwegian coast in order to improve weather forecasting (Bjerknes, 1919). The basic idea was introducing fronts into the daily weather chart by considering them as individuals, whose behaviour and dynamics can be studied separately from the air mass and thus in turn can be tracked from chart to chart. V. Bjerknes and his colleagues were not the first in doing so, this was Durand-Greville (1892), but they were the first who did it systematically over a longer period of time. It was the key experiment where the idea of a front was developed and the orographic influence was firstly discovered, such as the deformation of a front due to the impact of the Scandinavian mountains. Today it is well accepted that mountains play an important role in modifying fronts as is confirmed by the observations a round the world. In the 1920 's the elementary considerations on the impact of orography on fronts were formulated, however, until the 1980's no considerable improvement towards a quantitative understanding of this impact is noticeable. A review about the present state of knowledge regarding the topic "fronts and orography" is given in Egger and Hoinka (1992) and Blumen (1992).

A great problem encountered in experimental efforts on fronts is that a scale dependent separation of the processes associated with the fronts is almost impossible and it is therefore necessary that the measurement systems collect data which need to cover a broad range of scales. This is because the scale of the front is two magnitudes smaller than the scale of the forcing systems, such as cyclones, in which the front itself is imbedded; on the other hand the scale of the front is two magnitudes larger than the scales relevant to the frontal weather, which contains e.g. turbulence and precipitation. Considering an experimental effort of today the problem of fronts being modified by mountains has in general two aspects: the lack of observations with proper resolution and the lack of physical understanding. 
Fronts cross the north Alpine foreland on about 75 days each year, and they cause approximately $50 \%$ of the annual precipitation (Hoinka, 1985). This elucidates the strong impact of fronts on the weather and climate of the north Alpine region itself and the adjacent foothills of Switzerland, southern Germany and Austria. Fronts are observed to be deformed or slowed down, but they can also be intensified or rapidly shifted along the borders of the Alps. A recent example for the latter case is discussed in Volkert et al. (1991).

In order to study the impact of the European Alps on cold fronts the German Science Foundation(DFG) and Austrian, German and Swiss institutions sponsored a programme under the title "Fronts and Orography"; the "German Front Experiment 1987" (GFE87) constituted the major experimental achievement within this programme. In the GFE87 the meteorological university institutes in Cologne, Karlsruhe and Munich took part. Non-university contributions came from the "Institut für Atmosphärische Umweltforschung" of the Fraunhofer Society (in Garmisch) and from the "Institut für Physik der Atmosphäre" of the DLR (in Oberpfaffenhofen). The civilian and military German weather services contributed by increased observing frequency (rawinsondes) and by special forecasts. International co-operations existed with the weather services in Austria, Switzerland and with the operation centre of FRONTS87 in Bracknell/U.K. (see below). Having in mind the support of Austrian and Swiss groups the name of the experiment is somewhat misleading and a name such as "European Front Experiment" would have been more appropriate. The outline of the experiment is published elsewhere (Hoinka and Volkert, $1987 \mathrm{a}, \mathrm{b})$. Details on the conduct of the experiment can be found in Hoinka et al. (1988).

The climatology of European cold fronts, along with logistical considerations, determined the timing of the GFE87 from 1 October to end of December 1987, a period during which about five cold fronts per month could be anticipated above the Alps (Hoinka, 1985). The number of cold fronts per month for the rest of the year is also about five, but the fronts during the last three months of the year are usually associated with a stronger change in air mass than those occurring in spring or summer. Thus the fronts occurring during the last three months of the year are more intense; additionally at this time of the year foehn is a frequent prefrontal phenomenon. Finally, the main experimental effort (FRONTS87) within the joint British/French undertaking "Mesoscale Frontal Dynamics Project" (MFDP) was performed at the same time (Clough, 1987), which offered the unique chance of probing an orographically modified front by the GFE87, which was already measured in an undisturbed condition over sea.

The main purpose of the GFE87 was to collect high resolution data in order to investigate the structure and the development of orographically influenced cold fronts in the vicinity of the Alps. The central scientific objectives of the experiment were

- to document a few prominent fronts in different horizontal scales when they cross central Europe;

- to determine the orographic modification on these fronts; and

- to explain the physical mechanisms of the orographic modification.

The outline of the experiment must be seen as to improve our understanding; and thus in turn improve the analysis of fronts above orography; and finally, thus in turn improve the forecast of fronts and its associated weather under the influence of orography. With this in mind, a circled link between the first front experiment in 1918 and the present effort is obvious.

A first preliminary step was to find out the major problems in the analysis and in the forecast of cold fronts in the vicinity of the Alps as seen by weather forecasters working in the daily routine (Hoinka and Smith, 1986). As a result of this and as a guide for specific objectives of research concerning the orographic modifications of fronts several hypotheses have been formulated, which were to be assured or rejected (Hoinka and Volkert, $1987 \mathrm{~b}$ ). Although these hypotheses were formulated in the framework of the experiment and therefore stimulated by the experiment, they cover clearly much more than purely experimental efforts.

In this study it is tried to answer how far these hypotheses have been treated in the post-experimental phase and what we did learn from the experiment. The answer to this question can only be a subjective one as it depends on the degree of one's ignorance. We have selected the following scientific subjects: the orographically induced 
frontogenesis, the interaction of foehn and front, orographically trapped gravity currents, the flows in to the valleys and the modification of precipitating patterns by the Alps. Clearly, most results are not related purely to observational data. Therefore, we discuss the observations in combination with results from numerical simulations.

The plan of the paper is as follows: in section 2 we summarize the conduct of the experiment; in section 3 we describe the appearance of the fronts during all four intense observation period; section 4 reviews the findings made during the data analysis; in section 5 we address problems related to frontal analysis; finally, in section 6 , concluding remarks are compiled.

\section{The Conduct of the Experiment}

For a paper on the scientific results of a field experiment it is more important to discuss the scientific aims and the accomplishment of the programme than its design. As the experimental plan is published elsewhere (Hoinka and Volkert, $1987 \mathrm{a}$, b), only the general outline of the GFE87 is mentioned here.

There were an outer and an inner experimental area; the outer one was to specify the flow undis-

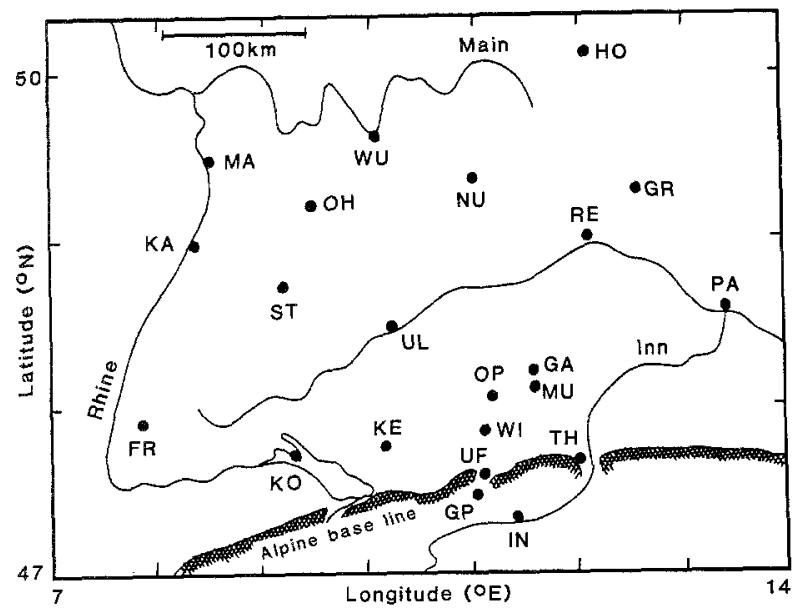

Fig. 1. Map of locations mentioned in the text. Freiburg (FR), Garching (GA), Garmisch-Partenkirchen (GP), Großer Arber (GR), Innsbruck (IN), Hof (HO), Karlsruhe (KA), Kempten (KE), Konstanz (KO), Mannheim (MA), München (MU), Nürnberg (NU), Oberpfaffenhofen (OP), Öhringen (OH), Passau (PA), Regensburg (RE), Stuttgart (ST), Thalreit (TH), Uffing (UF), Ulm (UL), Wielenbach (WI), Würzburg (WU) turbed by the Alps, the inner one the orographic effects. All special observing systems were concentrated in the inner area: north of the Alpine baseline and in the valleys of river Loisach and river Inn (see Fig. 1). An ideal front was envisaged to approach the Alps from the west or the northwest, being already recorded by the rawinsonde network of the outer area. Two radars collected three-dimensional data while different aircraft executed cross-sections in several heights normal to the front and parallel to it. Special aerological and ground stations at the baseline, in the two Alpine valleys and on some mountains registered the direct contact of fronts with the orography. For the experiment itself the proven method of "Intense Observing Periods" (IOP) was used; during these IOPs initiated by the steering group intense observations were undertaken by all platforms and stations. The IOPs lasted around 24 hours and were an effective and economic way to ensure maximum activity during important events. An extended description of the collected data is given by Hoinka et al. (1988).

Weather and the "Saint Fronto"1 were so cooperative to provide four strong cold fronts during the experimental period: 8 October (IOP-A), 12 November (IOP-B), 13/14 November (IOP-C) and 19 December 1987 (IOP-D). Beside these fronts also weak (13) and moderate (5) cases occurred. This reveals that the overall number of frontal passages during the chosen period of 1987 fits to the climatological ten year mean (Hoinka, 1985).

\section{The Appearance of the Fronts}

To become acquainted with IOPs A to D we first inspect the daily charts of European scale published in the "Berliner Wetterkarte" (Fig. 2). The progression of the surface fronts is studied using the subjectively analysed three-hourly surface charts for western and central Europe (Fig. 3) and analyses of the hourly complete set of SYNOP and METAR observations obtained in southern Germany and adjacent regions (Fig. 4), respectively. A second sub-section deals with the structure of the fronts as it appears in serial radiosoundings

\footnotetext{
1 "Saint Fronto" was the bishop of Perigneux (France) and today he still is the patron saint of this town. He is renowned for the miracle of double presence by having slept during the services and at the same time having buried the holy Martha somewhere else.
} 


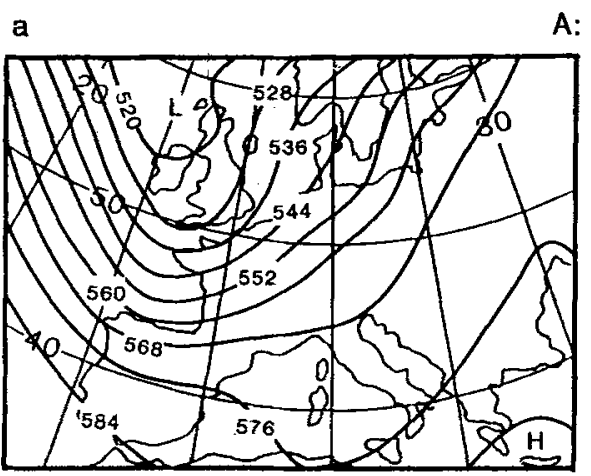

A: 8 October 1987

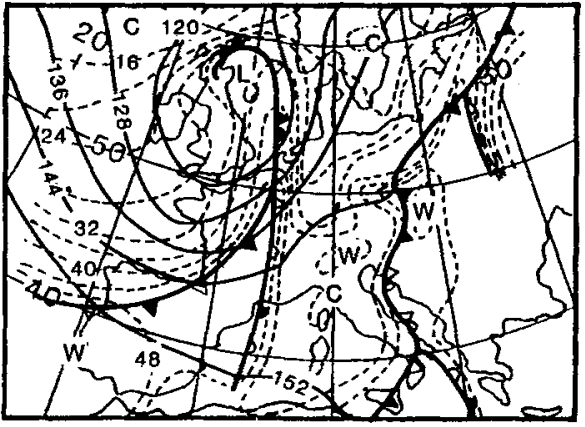

c

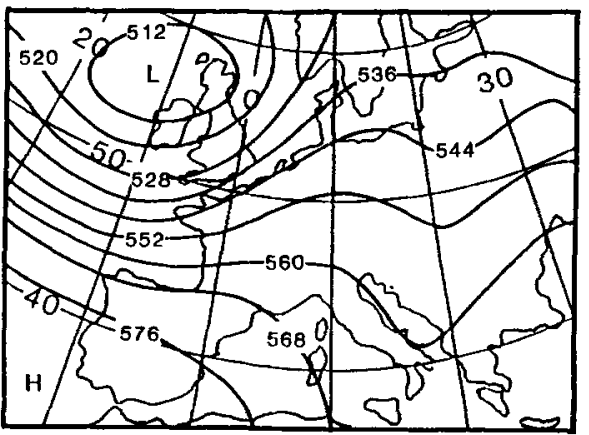

e

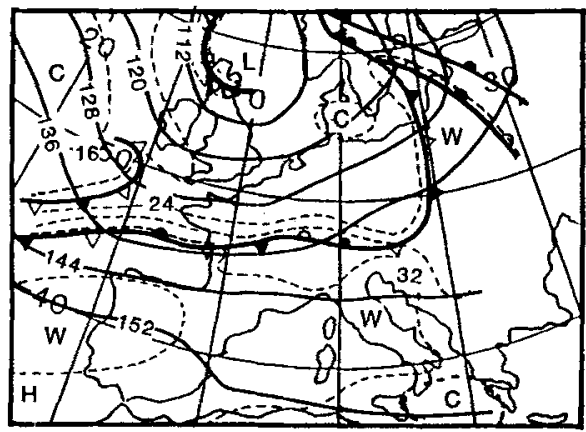

g

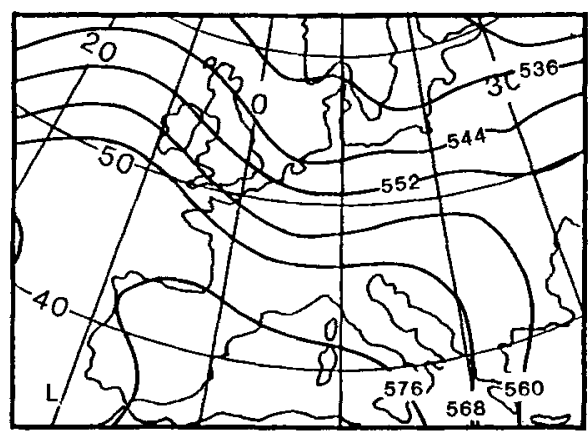

B: 12 November 1987

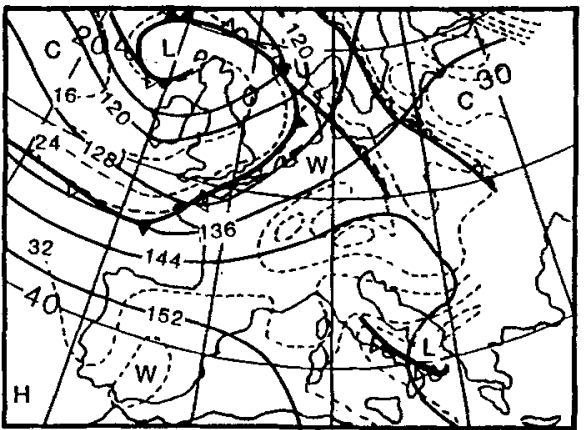

C:
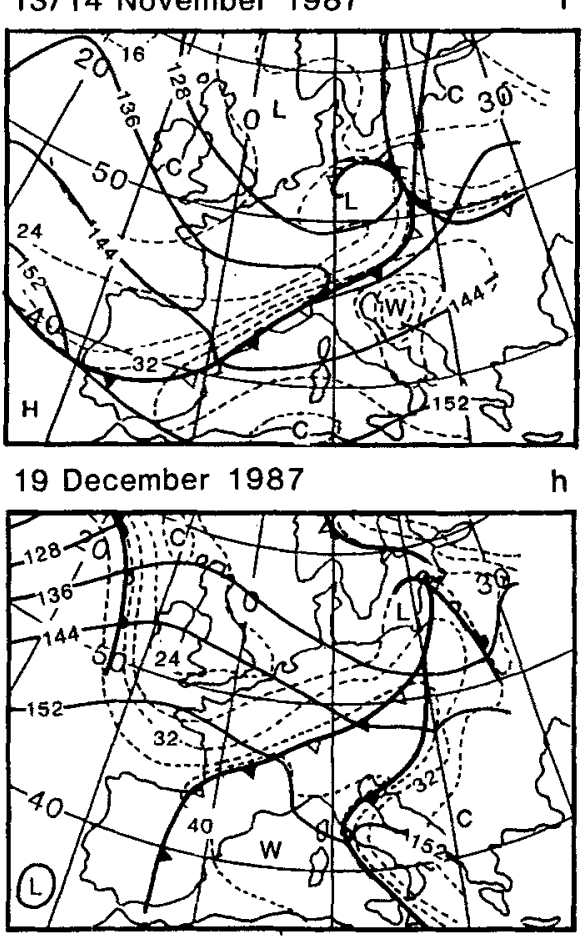

Fig. 2. Geopotential (full lines) and equivalent potential temperature (dashed lines) during the four IOPs. 8 October 1987, 00 UTC: $850 \mathrm{hPa}$ (a) and $500 \mathrm{hPa}$ (b); 12 November 1987,00 UTC $500 \mathrm{hPa}$ (c) and $850 \mathrm{hPa}(\mathrm{d}) ; 13$ November 1987, 00 UTC: 850 hPa (e); 14 November 1987, 00 UTC: $850 \mathrm{hPa}$ (f); 19 December 1987, 00 UTC: $500 \mathrm{hPa}(\mathrm{g})$ and $850 \mathrm{hPa}(\mathrm{h})$. Adapted from the "Berliner Wetterkarte" of a single station and in time series of several groundstations.

\subsection{On the Progression of the Fronts}

\subsubsection{IOP-A: Front of 8 October 1987}

On 8 October, 00 UTC, a distinct mid-tropospheric trough was situated over the British Isles and the
Bay of Biscay (Fig. 2a) with a half occluded frontal system below its leading edge (Fig. 2b). Three airmasses were present in the lower troposphere as revealed by equivalent potential temperature: prefrontal air $\left(\theta_{e} \approx 35^{\circ} \mathrm{C}\right)$, warm sector air $\left(\theta_{e} \approx 45^{\circ} \mathrm{C}\right)$ and postfrontal air $\left(\theta_{e}<30^{\circ} \mathrm{C}\right)$. The hourly observations from southern Germany indicate that the cold front crossed the river Rhine at 07 UTC 

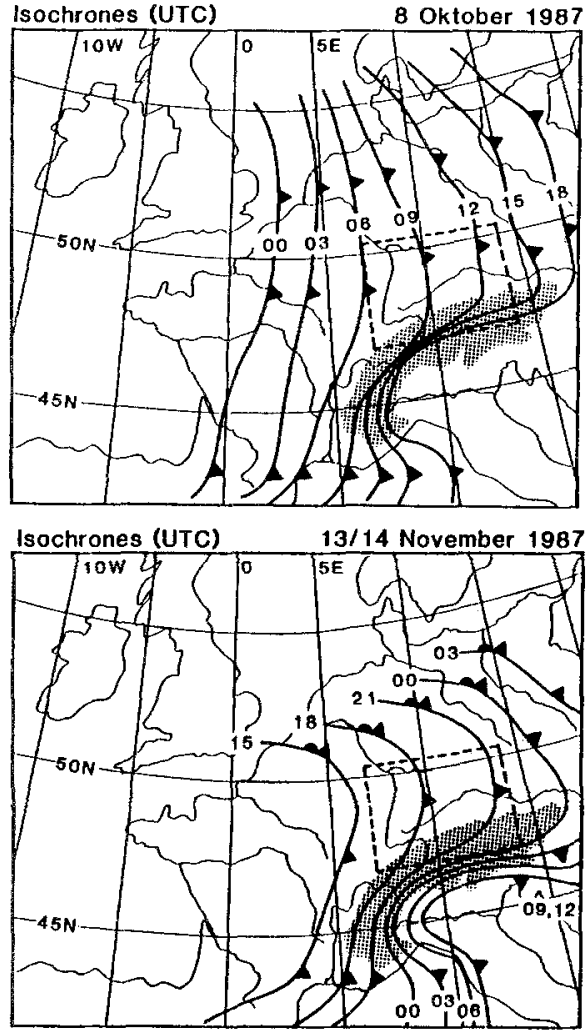
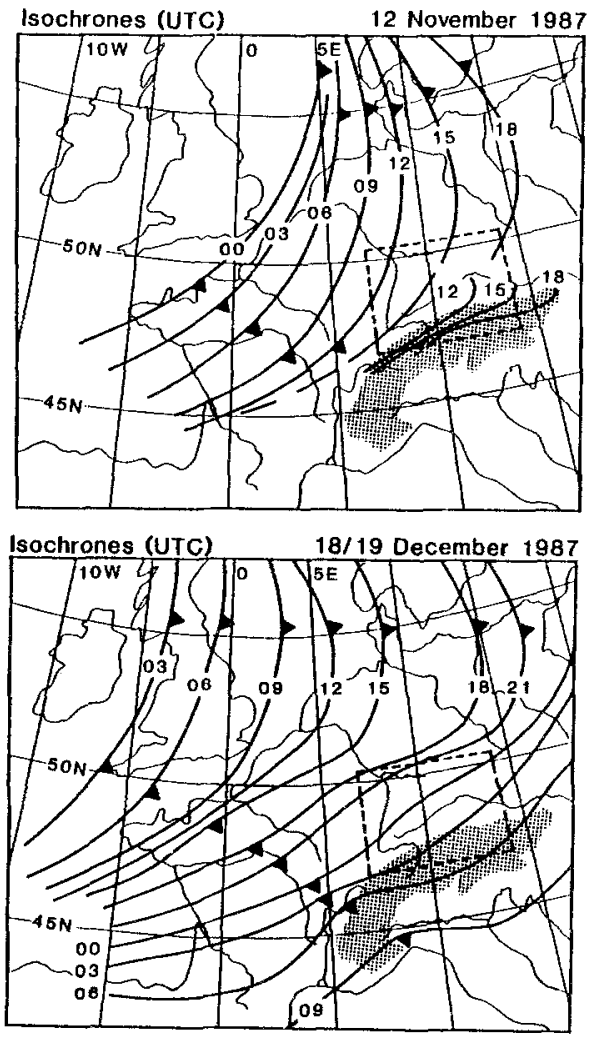

Fig. 3. Three-hourly isochrones of surface front position over central Europe for the four IOPs. The broken lines indicate the mesoscale area of Fig. 4. Adapted from Kurz (1990) approximately $100 \mathrm{~km}$ behind a preceding warm front (not displayed in Fig. 4). By that time heavy rain was observed in the Rhine area. At Karlsruhe $4 \mathrm{~mm}$ were recorded during the 6 hours after the passage of the front. At 09 UTC the cold front had caught up the warm front and had become the dominant surface feature. Figure 3 reveals how this front was blocked by the Alps in its southern part while it progressed quite uniformly over the north Alpine foreland (Fig. 4). The cross-frontal temperature difference at the $850 \mathrm{hPa}$ level increased from $2 \mathrm{~K} / 100 \mathrm{~km}$ over France to $6 \mathrm{~K} / 100 \mathrm{~km}$ over the Alpine foreland (Kurz, 1989).

\subsubsection{IOP-B: Front of 12 November 1987}

On 12 November, 00 UTC, the geopotential height pattern exhibited again a trough extending from Ireland to the Bay of Biscay (Fig. 2c). This time the warm sector was wider and extended further to the north (Fig. 2d). Its maritime subtropic air had equivale't potential temperatures of about $30^{\circ} \mathrm{C}$, while e was below $20^{\circ} \mathrm{C}$ within the maritime polar air behind the cold front. The threehourly isochrones (Fig. 3) indicate an eastward movement north of $50^{\circ} \mathrm{N}$ and a separate disturbance at the northern rim of the Alps. The pro- gression of the front into the Mediterranean area was hindered by the subsequent formation of two frontal waves along the 45 th parallel of latitude. In the mesoscale, a uniformly moving cold front was analyzed, which changed its orientation from northeast-southwest to north-south (Fig. 4). This front got slackened along the northern rim of the Alps. Furthermore, a slower moving, partly stationary, convergence line was found ahead of this front. The prefrontal discontinuities in Figs. 3 and 4 appear to have different orientations. This may be due to the different data densities of the synoptic and mesoscale analyses and to the different analysts.

\subsubsection{IOP-C: Front of 13 November 1987}

Along the elongated cold front of IOP-B two waves had developed on 13 November, 00 UTC (Fig. 2e). The western one lay in the vicinity of a vorticity maximum below the mid-tropospheric baroclinic zone and next to a comma cloud formation as is apparent in the satellite image (see Zwatz-Meise, 1989). The wave deepened and became a marginal low of the cyclone over the North Sea. On 14 November, 00 UTC, it was situated over northern Germany (Fig. 2f). Consequently a 

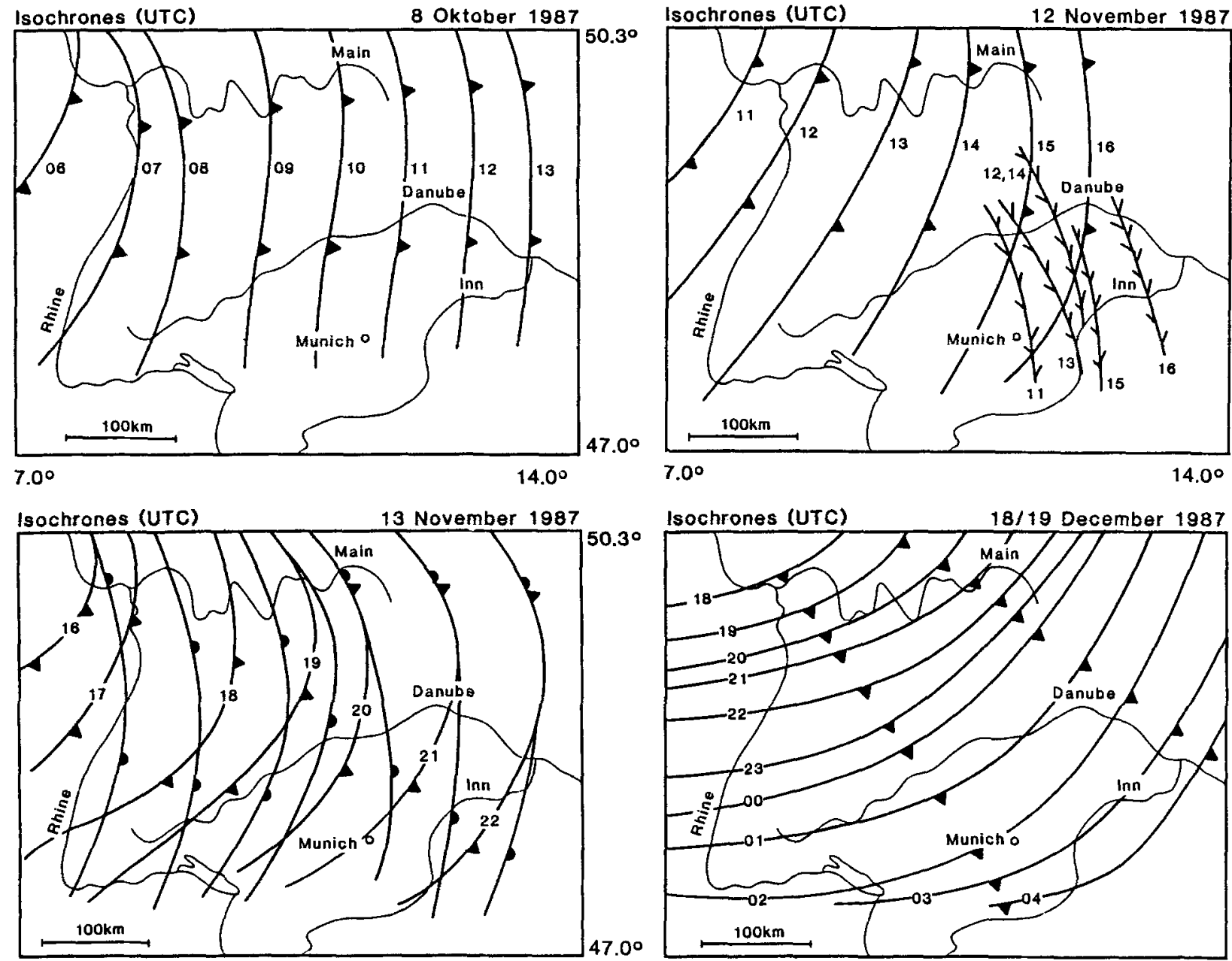

Fig. 4. Hourly isochrones of surface front position over southern Germany for the four IOPs. The feathered lines (12 November 1987) indicate a slow moving prefrontal convergence line

distinct contrast in equivalent potential temperature $\left(\Delta \theta_{e}>10 \mathrm{~K}\right)$ formed between subtropic air in the east and intruding polar air in the west. The front was clearly deformed by the Alps (Fig. 3). In the mesoscale analyses a warm and a cold front were observed with a gradually diminishing warm sector between them as both fronts moved towards the east (Fig. 4).

\subsubsection{IOP-D: Front of 19 December 1987}

A ridge over the eastern Atlantic and a shallow trough over France characterized the $500 \mathrm{hPa}$ height field on 19 December, 00 UTC (Fig. 2g). Below the trough's leading edge a large sector of warm and moist subtropic air is present in the $850 \mathrm{hPa}$ level (Fig. 2h). The synoptic chart of the surface front positions shows a westward propagation of the front's northern part with accelera- tion across northeastern Germany, whereas its southern part crossed the Alps quite undisturbed from the northwest to the southeast (Fig. 3). The mesoscale analysis for southern Germany suggests that the front was accelerated after 00 UTC on 19 December (Fig. 4).

An estimate of the frontal speed and orientation over southern Germany was evaluated from the isochrone charts combined with timings of pressure jumps (cf. Figs. 6,7 and 8) and temperature drops (see also Hoinka et al., 1990). They are listed in Table 1. In summary we state that of the four frontal events there were three cases with prefrontal foehn (IOPs A, B and C); three fronts came from the west (IOPs A, B and C); one was from the northwest (IOP-D); two were strongly deformed by the Alps (IOPs A and C); one crossed the Alps without being disturbed (IOP-D); and one got slackened along the northern Alps (IOP-B). 
Table 1. Direction of the Frontal Propagation, $\alpha$, and Propagation Velocity, $c$, for the Events of the GF E87 (after Freytag, 1990)

\begin{tabular}{lrrrr}
\hline Frontal event & $\mathrm{A}$ & $\mathrm{B}$ & $\mathrm{C}$ & $\mathrm{D}$ \\
\hline$\alpha$ in deg & 270 & 285 & 295 & 325 \\
$\mathcal{c}$ in $\mathrm{m} \mathrm{s}^{-2}$ & $\approx 20$ & $\approx 18$ & $\approx 20$ & $\approx 12$ \\
\hline
\end{tabular}

During the IOPs $\mathrm{A}, \mathrm{B}$ and $\mathrm{C}$ precipitation was recorded ahead and behind of the front, with the exception that in the area with prefrontal foehn in southern Germany no precipitation occurred. IOP-D is characterized by a broad area with precipitation ahead and behind of the front; this pre- cipitation was intensified close to the Alps due to blocking effects.

\subsection{Frontal Structure in Time Series}

Inspection of time series obtained from ground stations or of time-height cross-sections constructed from serial radiosoundings is a common tool to document the changes of meteorological parameters during the passage of a front. In this sub-section we use for that purpose the rawinsonde station of Thalreit close to the Alpine baseline because of its high sounding frequency (one ascent every 1.5 hours; Fig. 5), the meteorological tower of Garching ( $20 \mathrm{~km}$ north of Munich; Fig. 6) and three sensitive recording microbarographs (Figs. 7 and 8).
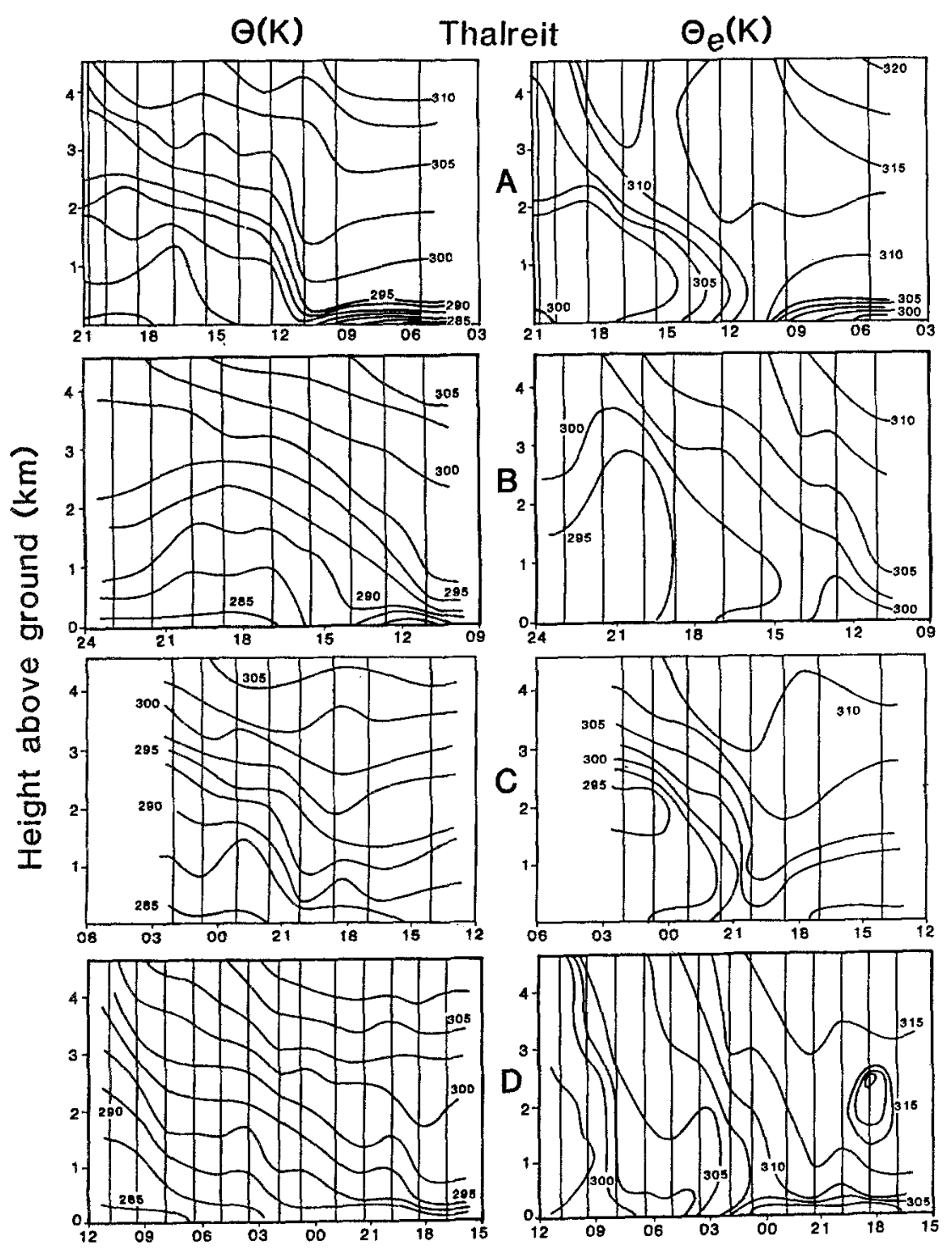

Fig. 5. Time-height cross-sections of potential temperature $\theta$ (left) and equivalent potential temperature $\theta_{e}$ (right) at Thalreit for IOPs A, B, C and D. The vertical lines indicate the soundings. The time scale runs from right to left to give the correct

Time (h) sense of the spatial structure 

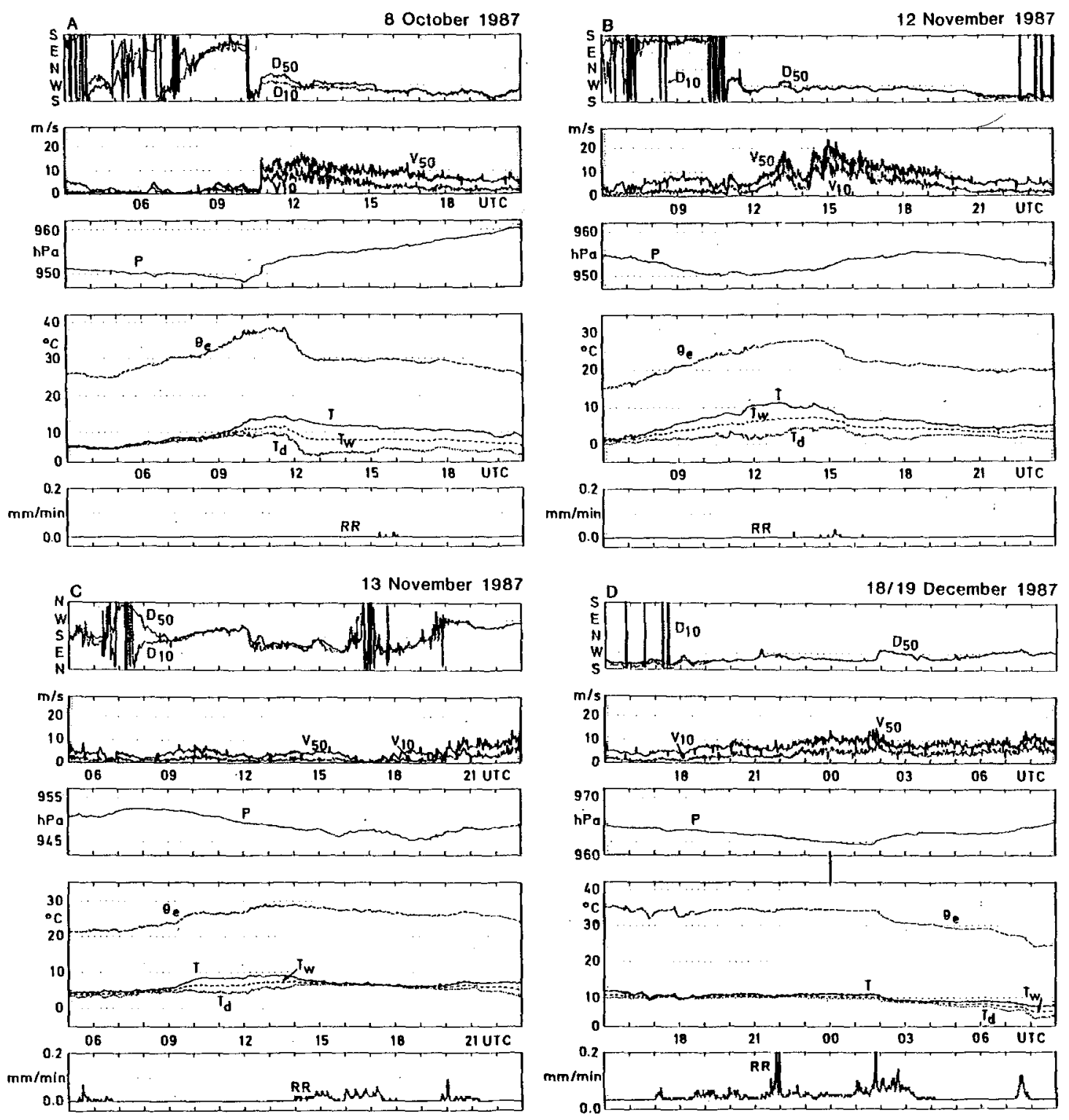

Fig. 6. Time series recorded at Garching with measuring interval of $30 \mathrm{~s}$. The symbols stand for (from top to bottom): wind direction in 10 and $50 \mathrm{~m}\left(D_{10}\right.$ and $\left.D_{50}\right)$; wind speed in 10 and $50 \mathrm{~m}\left(v_{10}\right.$ and $\left.v_{50}\right)$; pressure (p); equivalent $\left(\theta_{e}\right)$, dry $(T)$, wet bulb $\left(T_{w}\right)$ and dew point temperatures $\left(T_{d}\right)$ in $2 \mathrm{~m}$; rain rate $(\mathrm{RR})$

\subsubsection{IOP-A: Front of 8 October 1987}

Figure $5 \mathrm{~A}$ shows the time-height cross-sections of potential and equivalent potential temperatures at Thalreit on 8 October between 03 and 21 UTC. The front crossed the site at 1115 UTC. Its passage is clearly marked by a gradient zone in $\theta$ and $\theta_{e}$ which bends backward with height. Over an interval of $3.5 \mathrm{~h}$ (approx. equivalent to a distance of $200 \mathrm{~km}) \theta_{e}$ decreases by more than $7 \mathrm{~K}$. Doppler radar data taken at Oberpfaffenhofen and sound- ing data taken at Munich suggest a relative crossfrontal flow towards the front from its rear side so that the colder air mass appears coming from aloft (Hoinka et al., 1990).

East of the transition zone, a marked inversion is observed close to the ground. In the pre-frontal area a southerly foehn flow was observed. Frequently such foehn flows do not touch the ground some distance off the Alpine baseline, i.e. the warm air does not replace the pre-existing cold air and glides up on a shallow surface-based cold layer (Hoinka and Rösler, 1987). This layer is topped 


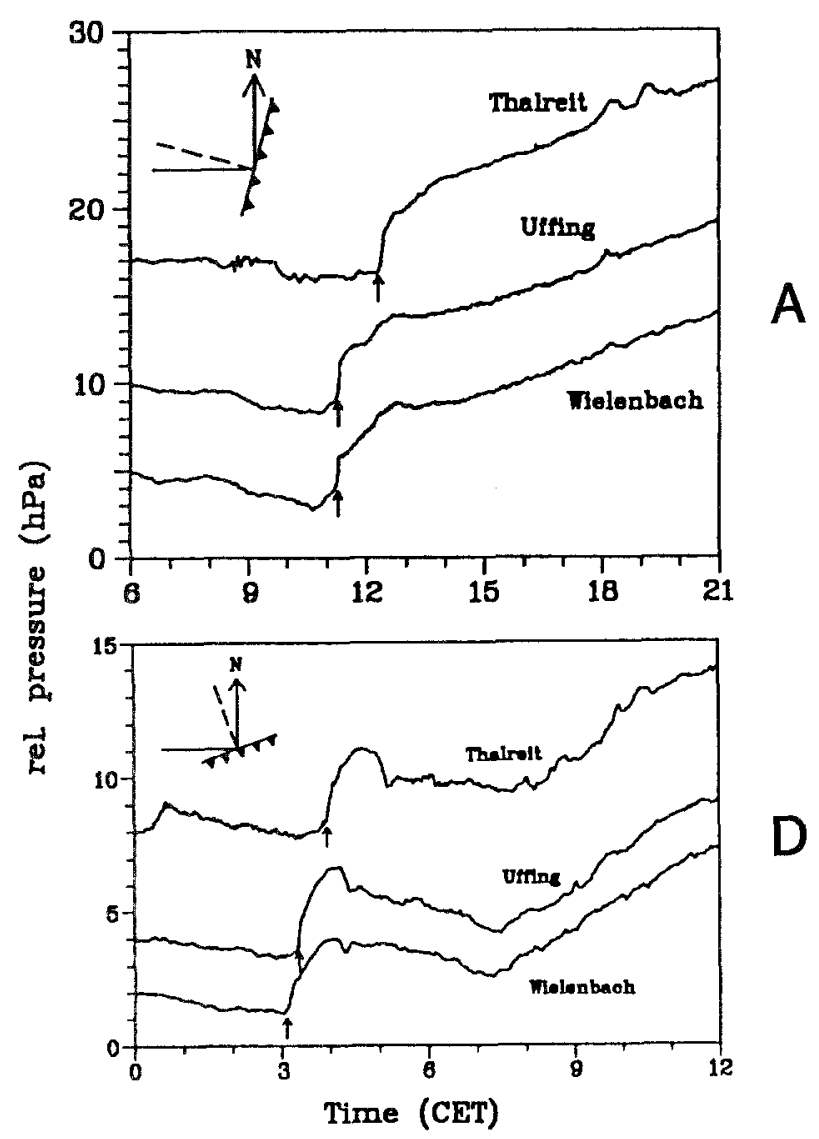

Fig. 7. Pressure traces, relative to an arbitrary mean, at three stations in the Alpine foreland: 8 October (IOP-A, top) and 19 December (IOP-D, bottom). Taken from Müller and Sladkovic (1990)

by an inversion which is apparent in Fig. 5A in the lowest $500 \mathrm{~m}$ for times prior to 09 UTC.

The front passed Garching at 1044 UTC and was accompanied by a distinct and abrupt pressure jump of $1.8 \mathrm{hPa}$ within $4 \mathrm{~min}$ (Fig. $6 \mathrm{~A}$ ). Similar jumps were observed in Wielenbach, Uffing and Thalreit somewhat later (Fig. 7A). The pressure jump was accompanied by a sudden gust and veering of the wind direction from the southsouthwest towards the west at $10 \mathrm{~m}$ and towards the northwest at $50 \mathrm{~m}$. In the temperature traces, a slight increase followed by a reduction of humidity one hour later can be seen. This becomes most significant in the decrease of the equivalent potential temperature by $9 \mathrm{~K}$ within less than one hour (Fig. 6A).

\subsubsection{IOP-B: Front of 12 November 1987}

Figure $5 \mathrm{~B}$ shows the time-height cross-sections at Thalreit on 12 November between 09 and 24
UTC. The front reached this station at 1220 UTC; this and the following times of frontal passages are based on pressure readings. For this event the frontal passage is only weakly marked in the potential temperature. The prefrontal surfacebased cold air is apparent which was also due to the prefrontal foehn. The occurring inversion is weaker than that during IOP-A. The postfrontal cooling at the lowermost $2 \mathrm{~km}$ stops around 20 UTC.

At the surface in Garching a significant drop in temperatures is not obvious when the front passed at 1130 UTC (Fig. 6B); the wind shifted from the southwest towards the northwest at 1100 UTC with a gradual and intermittent increase in speed. Four hours later, at 1540 UTC, the equivalent potential temperature dropped by $3 \mathrm{~K}$ after a short period of light rain. In the pressure traces of Uffing and Thalreit (Fig. 8B) there is an abrupt pressure rise with a low amplitude at noon, which is possibly correlated with the prefrontal convergence line (Fig. 4).

\subsubsection{IOP-C: Front of 13 November 1987}

Figure $5 \mathrm{C}$ shows the time-height cross-sections at Thalreit between 13 November, 12 UTC and 14 November, 03 UTC. The front passed the station at 2015 UTC. The frontal passage of this event is well marked about $1000 \mathrm{~m}$ above ground in both temperatures whereas at the surface the gradients are significantly weaker.

This front was associated with a distinct pressure jump in the early evening hours. Closer to the Alps, this jump was stronger $(\Delta p>2 \mathrm{hPa}$; Fig. $8 \mathrm{C})$ than further to the north, at Garching $(\Delta p \approx 1 \mathrm{hPa}$; Fig. $6 \mathrm{C})$. The time series of Garching do not appear very dramatic when the front passed the station at 1930 UTC. The wind attained only half the strength it had the afternoon before (Fig. 6B), it increased around the small nose in pressure at 1925 UTC and veered from easterly to westerly directions. The temperature traces are insignificant. There was some rain, with a maximum intensity half an hour after the passage of the pressure disturbance.

\subsubsection{IOP-D: Front of 19 December 1987}

Figure 5D shows the time-height cross-sections at Thalreit between 18 December, 15 UTC and 19 December, 12 UTC. The front passed at 0345 


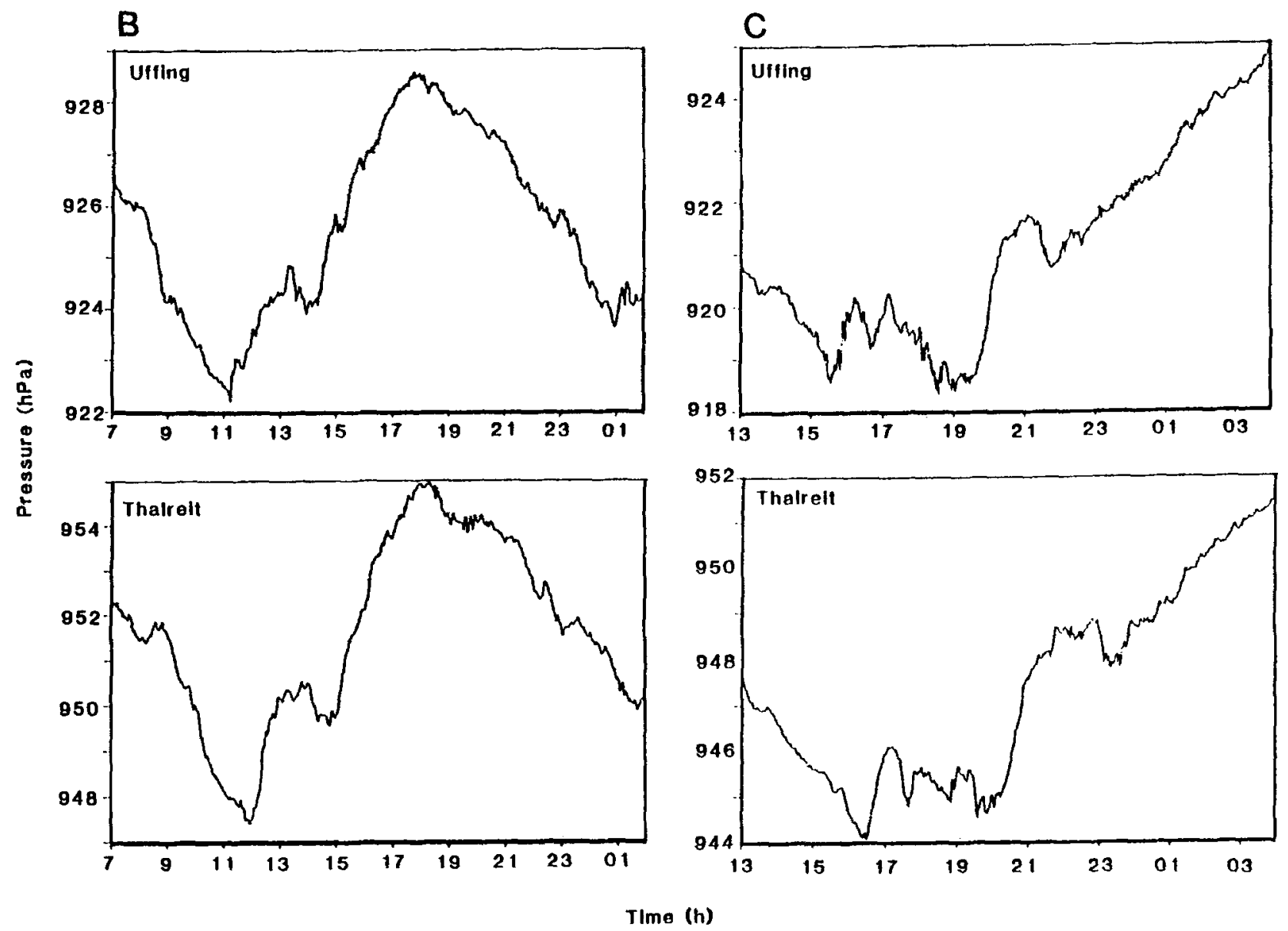

Fig. 8. Pressure traces from Uffing and Thalreit: 12 October (IOP-B, left) and 13/14 October (IOP-C, right)

UTC. The gradients in $\theta_{e}$ are well marked whereas the gradients in potential temperatures are weak. The isolines of $\theta_{e}$ associated with the front are steeply inclined and go higher than $5 \mathrm{~km}$ which indicates the approach of a deep cold air mass which may explain why this front crossed the Alpine barrier relatively undisturbed (Fig. 3).

The station Garching was reached by the front at 0148 UTC which is reflected in a jump in pressure (Fig. 6D). Similar pressure jumps were recorded at the other stations (Fig. 7D). Associated with the pressure jump at Garching was a change in wind direction from $230^{\circ}$ to $290^{\circ}$, a maximum wind speed, a slight reduction of temperature, which is recognized best in the equivalent potential temperature. At the same time a high precipitation rate of about $0.8 \mathrm{~mm} / \mathrm{min}$ was recorded over two minutes (Fig. 6D; the maximum did not fit to the scale).

\section{The Findings}

In this section the findings from GFE87 are presented. They involve non-standard data evaluations and combine these with results from numerical simulations. Although certainly not complete, a kind of review is attempted which blends new results with those published since the end of the experiment. To this end Figs. 9 to 13 , $15,16,18$ to 20 are taken from the sources mentioned in the respective figure captions. Specifically, we discuss the following subjects in sequence: frontogenetical effects associated with the Alps; interaction of foehn and fronts; observational evidence of orographically trapped gravity currents; flow into valleys; and finally modification of the precipitation by the Alps.

\subsection{Frontogenetic Effects}

In this subsection three ways of analysing frontogenetical effects are collected. 


\subsubsection{Synoptic-Scale Diagnosis of the Frontogenesis Function}

Kurz (1990) performed a synoptic scale diagnosis based on rawinsonde data. The data were interpolated to a grid of $127 \mathrm{~km}$ from the manually analyzed height, velocity and temperature fields. Several terms of the frontogenesis function were derived as defined by Miller (1948). The horizontal part of this function is given by: $F_{H}=\partial \theta / \partial n \cdot \partial V_{N} / \partial n$. The spatial distribution of $F_{H}$ is given in Fig. 9 for IOPs A and B. At the $850 \mathrm{hPa}$ level values of up to $30 \cdot 10^{-10} \mathrm{~K} \mathrm{~m}^{-1} \mathrm{~s}^{-1}$ were diagnosed north of the Alps on both occasions (Fig. 8, top). At $700 \mathrm{hPa}$ about $70 \%$ of this value was attained. A comparison with other studies shows that these values are much stronger than those derived within frontal zones above flat terrain (see Table 2) suggesting that orography has a strong frontogenetic impact on the flow. However, one has to keep in mind that the resulting analysis indicates frontogenesis north of the Alps without demonstrating that these effects are due to the orography.

In a further step, Kurz (1990) estimated the forcing of the vertical motions using a modified Q-vector form of the omega-equation (Keyser et al., 1988). The spatial distribution of the omegaforcing during both events shows at 700 and $850 \mathrm{hPa}$ a strong descent at the cold side of the frontal zone north of the Alps. Kurz determined that this vertical motion partly compensates the frontogenetic effect of the horizontal wind so that only half of it remained as overall effect.

This kind of diagnosis is effective above flat terrain with some limitations. The frontogenesis due to the gradient in diabatic heating cannot be treated reasonably. The estimation of the frontolysis associated with mixing is also unclear (Hoinka, 1986). With mountains present the situation is
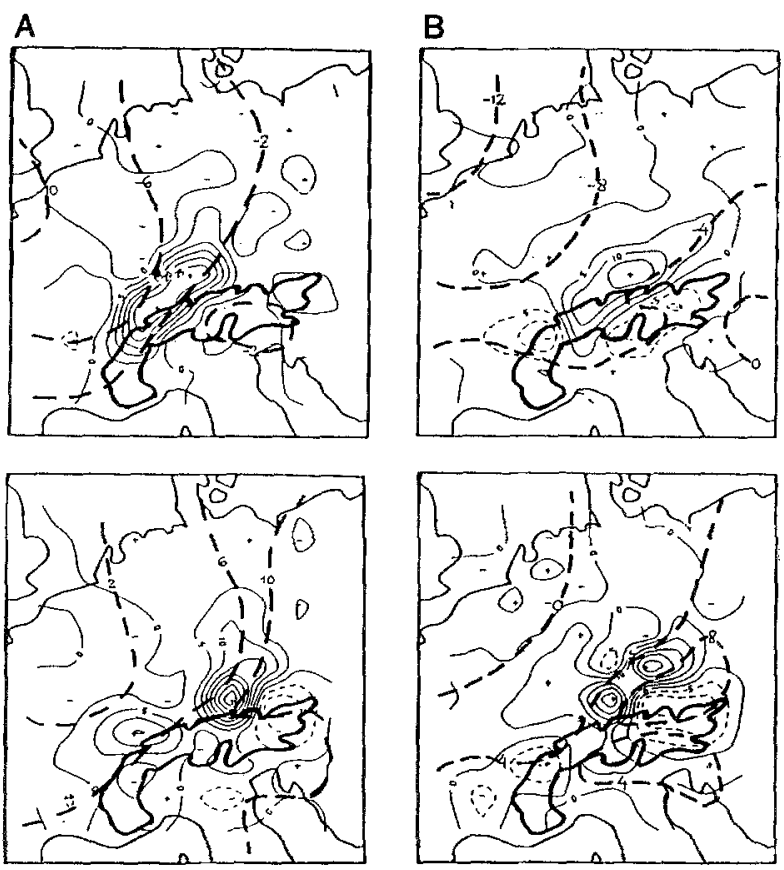

Fig. 9. Diagnosis for the $850 \mathrm{hPa}$ (bottom) and $700 \mathrm{hPa}$ level (top) on 8 October 1987 (IOP-A, left) and 12 November 1987 (IOP-B, right): frontogenesis function $F_{H}$ in $10^{-10} \mathrm{~K} \mathrm{~m}^{-1} \mathrm{~s}^{-1}$. Taken from Kurz (1990)

worse because it is not clear how to treat the effects of the mountains on the vertical motion field based on observational data, but at least in principle (or with the aid of a numerical model), the orographically induced vertical motion can be computed. The horizontal distribution of the vertical velocity is necessary to evaluate the term of the frontogenesis function which represents the tilting of the vertical gradient of $\theta$ into the horizontal by the component of the horizontal gradient of vertical velocity. Therefore, a strict interpretation of the frontogenesis function is at best valid for areas some distance away from the Alps.

Table 2. Typical Maximum Values of Frontogenetical Terms from Various Studies

\begin{tabular}{llll}
\hline Reference & $\left(F_{H}\right)$ or $\left(-u_{x} \theta_{x}\right)$ & $\left(-w_{x} \theta_{z}\right)$ & $\Delta x$ \\
& $10^{-10} \mathrm{~K} \mathrm{~m}^{-1} \mathrm{~s}^{-1}$ & $10^{-10} \mathrm{~K} \mathrm{~m}^{-1} \mathrm{~s}^{-1}$ & $\mathrm{~km}$ \\
\hline Baldwin et al. (1984) & 5 & -8 & 440 \\
Ogura and Portis (1982) & 20 & -20 & 90 \\
Garratt et al. (1985) & 10 & -15 & 30 \\
Hoinka (1986) & $4 / 16$ & $-100 /-20$ & $50 / 100$ \\
Kurz (1990) & 30 & - & 127 \\
\hline
\end{tabular}




\subsubsection{Cross-Frontal Gradients Through Time} Series Analysis

The inspection of cross-frontal gradients (as seen in time series) within a network of stations constitutes a simple and direct method to diagnose frontal contrasts at the surface. Freytag (1990) systematically studied pressure jumps as observed during IOPs A, B and D. He found the strongest contrast of about $3 \mathrm{hPa} / \mathrm{h}$ at about 20 to $60 \mathrm{~km}$ north of the Alpine baseline and considerably reduced magnitudes both further away and in the inner-Alpine portion of the Inn valley (Fig. 10). So, the vertically intergrated signal of a contrast in the mass field appears to be strongest near the Alpine baseline. From New Zealand increasing amplitudes of pressure jumps are reported across fronts as they propagate northward along the Southern Alps of New Zealand (Smith et al., 1991). A similar phenomenon is until now not reported for the European Alps.

Now we turn to the cross-frontal temperature contrasts. The "Papal Front" of 3 May 1987, which vigorously passed over the Alpine foreland during the preparation phase of the GFE87, may serve as an example (cf. Volkert et al., 1991). Table 3 summarizes the two-hourly temperature drops for 14 stations in southern Germany. The discontinuity clearly evolved whilst travelling along the northern rim of the Alps and was stronger closer to the baseline than further to the north. The same information was concisely visualized in Hartjenstein and Egger (1990) by combining the hourly temperature readings of Konstanz, München, and Nürnberg. In Konstanz the temperature gradually decreased by $7 \mathrm{~K}$ between 10 and 13 UTC, in München $(180 \mathrm{~km}$ further to the east and $50 \mathrm{~km}$ north of the Alpine baseline) a sudden drop by $10 \mathrm{~K}$ occurred shortly after 14 UTC, whereas a gentle decrease of $5 \mathrm{~K}$ between 15 and 18 UTC was recorded in Nürnberg $(150 \mathrm{~km}$ north of
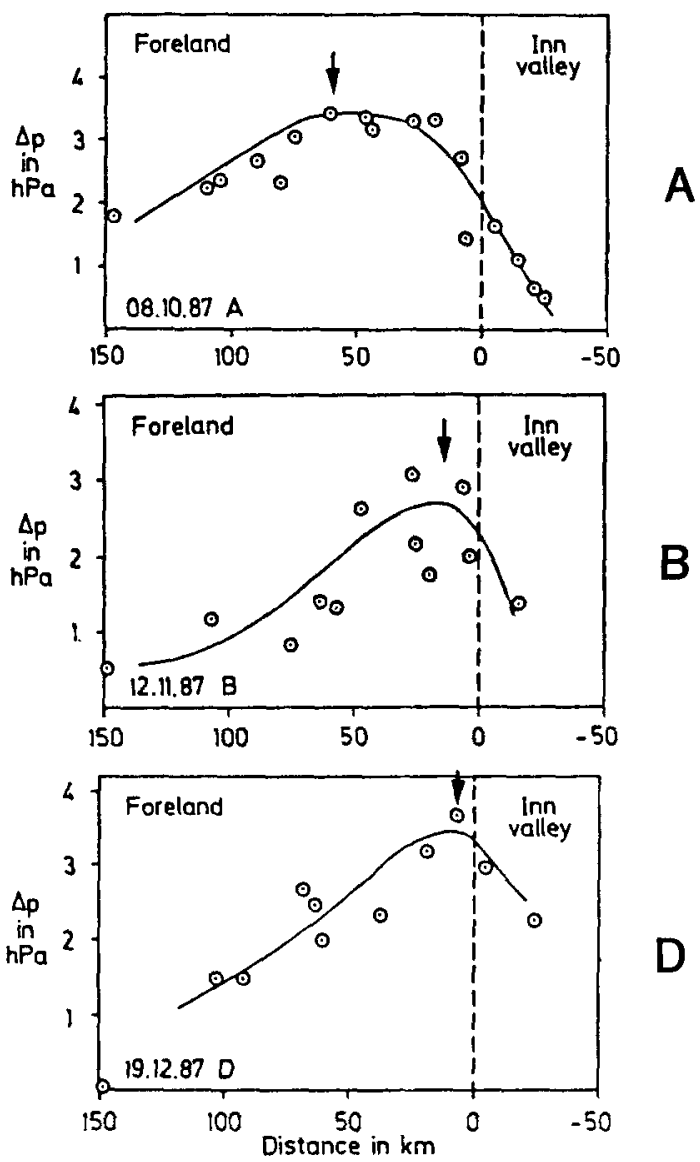

Fig. 10. Pressure rise $\Delta p$ after the passage of the cold fronts during the IOPs A, B and $\mathrm{C}$ in dependence of the distance from the Alps. Taken from Freytag (1990)

Munich). For another case, the cold front of 29 July 1985 , a collection of surface data was elaborated as in Table 3 (Hoinka, 1991); this exhibits the same trend as the data of the papal front, namely an increasing temperature contrast towards the east with the north-south maximum not far off the baseline. During the IOPs the temperature contrasts were not well marked at the surface. Yet, time-height cross-sections of virtual potential temperature obtained from the IOP-A soundings

Table 3. Two-Hourly Temperature Drops (K) Associated with the Papal Front of 3 May 1987 Towards the East Along Three Lines North of the Alps; Distances are measured from the Alpine baseline; see Fig. 1 for the locations

\begin{tabular}{|c|c|c|c|c|c|}
\hline$\approx 200 \mathrm{~km}$ & $\begin{array}{l}\text { Mannheim } \\
-6\end{array}$ & $\begin{array}{l}\text { Würzburg } \\
-7\end{array}$ & & & $\begin{array}{l}\text { Hof } \\
-2\end{array}$ \\
\hline $100-150 \mathrm{~km}:$ & $\begin{array}{l}\text { Karlsruhe } \\
-6\end{array}$ & $\begin{array}{l}\text { Öhringen } \\
-6\end{array}$ & $\begin{array}{l}\text { Nürnberg } \\
-4\end{array}$ & $\begin{array}{l}\text { Regensburg } . \\
-7\end{array}$ & $\begin{array}{l}\text { Gr. Arber } \\
-6\end{array}$ \\
\hline $30-70 \mathrm{~km}:$ & $\begin{array}{l}\text { Freiburg } \\
-6\end{array}$ & $\begin{array}{l}\text { Konstanz } \\
-5\end{array}$ & $\begin{array}{l}\text { Kempten } \\
-11\end{array}$ & $\begin{array}{l}\text { München } \\
--12\end{array}$ & $\begin{array}{l}\text { Passau } \\
-15\end{array}$ \\
\hline
\end{tabular}


of Thalreit and München indicate again that the thermal contrast is stronger close to the baseline (Hoinka et al., 1990).

\subsubsection{Cross-Sectional Analysis of Radiosonde Ascents}

Heimann and Volkert (1988) showed for the papal front that the gradients in $\theta$ and $\theta_{e}$ imbedded in a baroclinic zone diverge towards the surface up to $400 \mathrm{~km}$ (Fig. 11). All significant weather activity (thunderstorm, heavy precipitation, strong gusts) was linked to the western surface front with a strong contrast in $\theta_{e}$ (Table 4). Computations with a three layer model, which takes phase conversions into account (Heimann, 1988), indicated that the combination of diabatic and orographic effects was essential for that particular case.
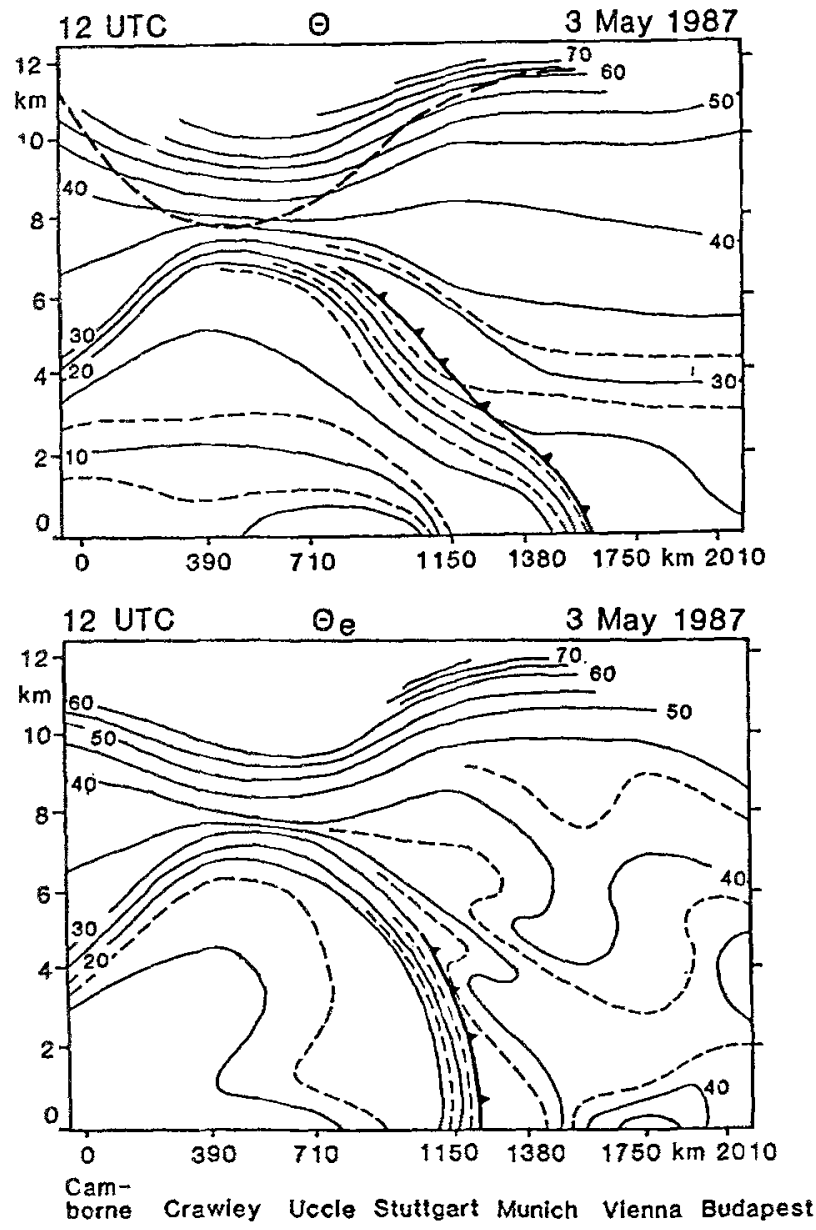

Fig. 11. West-east cross-sections of potential temperature $\left({ }^{\circ} \mathrm{C}\right.$; top) and of equivalent potential temperature $\left({ }^{\circ} \mathrm{C}\right.$; bottom). The position of the corresponding front lines are indicated by bold lines with frontal symbols. Taken from Heimann and Volkert (1988)
Table 4. Magnitude of Changes for Several Meteorological Elements During the Frontal Passage in Garching on 3 May $1987 ; T, T_{w}, \theta_{e}$ : dry, wet bulb, and equivalent potential temperatures; p: pressure; $v_{50}, D_{50}$ : wind speed and direction in $50 \mathrm{~m}$; RR: precipitation. The values give maximum changes in the corresponding parameters associated with the frontal passage. Taken from Heimann and Volkert (1988)

\begin{tabular}{lcc} 
& " $\theta$ "-front-line & " $\theta_{e} "$-front-line \\
\hline$\Delta T / \Delta t$ & $-2.0 \mathrm{~K} / 6 \mathrm{~min}$ & $-6.2 \mathrm{~K} / 6 \mathrm{~min}$ \\
$\Delta T_{w /} / \Delta t$ & $-1.9 \mathrm{~K} / 6 \mathrm{~min}$ & $-4.8 \mathrm{~K} / 6 \mathrm{~min}$ \\
$\Delta \theta_{e} / \Delta t$ & $-4.5 \mathrm{~K} / 6 \mathrm{~min}$ & $-12.0 \mathrm{~K} / 6 \mathrm{~min}$ \\
$\Delta p / \Delta t$ & $0.2 \mathrm{hPa} / 6 \mathrm{~min}$ & $1.8 \mathrm{hPa} / 6 \mathrm{~min}$ \\
$\Delta v_{50} / \Delta t$ & $6 \mathrm{~m} \mathrm{~s}-1 / 8 \mathrm{~min}$ & $16 \mathrm{~m} \mathrm{~s}^{-1} / 8 \mathrm{~min}$ \\
$\Delta D_{50} / \Delta t$ & $20^{\circ} / 8 \mathrm{~min}$ & $90^{\circ} / 8 \mathrm{~min}$ \\
$R R / \Delta t$ & 0 & $3.1 \mathrm{~mm} / 6 \mathrm{~min}$
\end{tabular}

But even for the weaker front of IOP-A and within the smaller area of the dense radiosounding network distinct differences of the patterns in $\theta$ and $\theta_{e}$ were found in the lower half of the tropo-

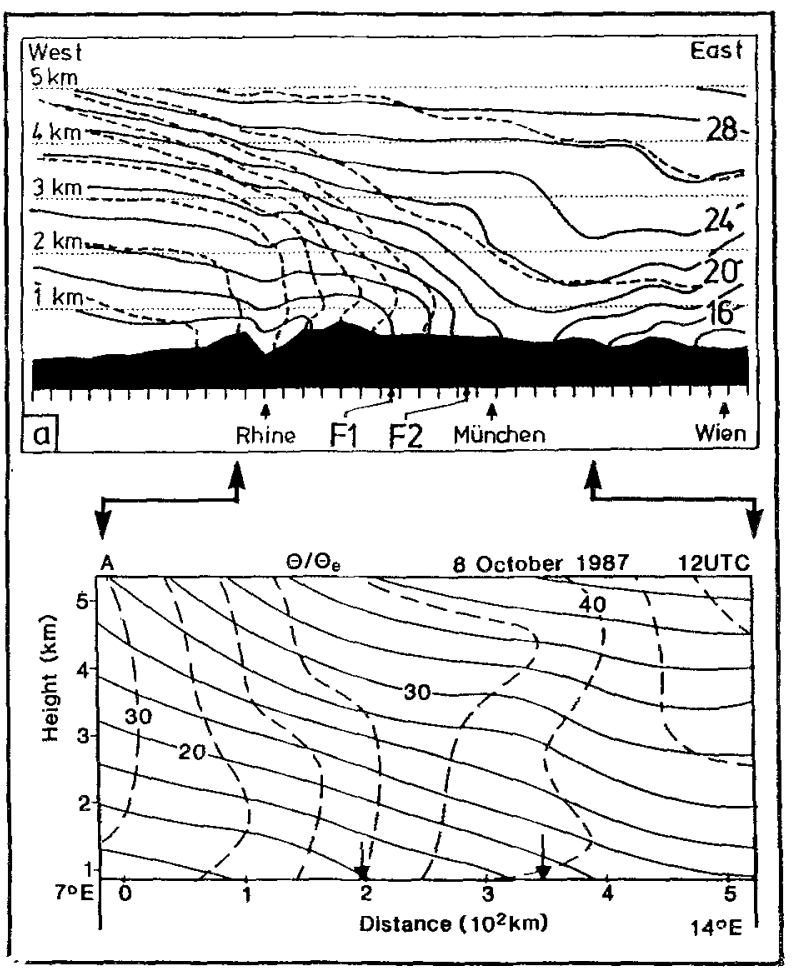

Fig. 12. Vertical east-west cross-section along $48.5^{\circ} \mathrm{N}$ as computed with a numerical model (top; Heimann, 1990) and a mesoscale analysis of radiosonde data on 8 October 1987 , 12 UTC (bottom). The isolines of $\theta$ (full) and $\theta_{e}$ (dashed) are labeled in ${ }^{\circ} \mathrm{C}$. The arrows in the bottom figure indicate the location of the maximum of the horizontal gradients in $\theta_{e}$ (left) and $\theta$ (right) 
sphere. A west-east cross-section through objectively analysed radiosonde data (for more details see Thorpe et al., 1992) is displayed in Fig. 12 (bottom). A gentle sloping field is found for $\theta$ whereas $\theta_{e}$ does not exhibit much variation with height below $3 \mathrm{~km}$. A very similar separation of gradient zones in $\theta$ and $\theta_{e}$ is found in synthetically initialized model calculations of Heimann (1990; Fig. 12, top). Although mesoscale dropsonde analyses over the eastern Atlantic (Thorpe and Clough, 1991) show a similar structure in the absence of orography, a more thorough investigation, which combines observations of the GFE87 and model calculations, indicates clearly that the separation is emphasized close to the Alps (Heimann, 1992b).

In this sub-section some hints were collected that the Alps act frontogenetically on approaching fronts. However, experienced weather forecasters emphasize that fronts may also dissolve (Hoinka and Smith, 1986). Such cases were not reported in publications related to GFE87. Presumably, it is less difficult to recognize an intensification of a front than its smooth decay.

\subsection{Foehn and Fronts}

Early in our century v. Ficker was the first who pointed out that there is a strong linkage between foehn and the following cold air mass of a depression. He also mentioned that ground inversions mask a cold front, a situation which frequently occurs in the Alpine foreland during foehn (v. Ficker, 1926). Such an inversion results from a surface based cold air which is surmounted by the warm foehn air (Hoinka and Rösler, 1987). Thus the temperature drop associated with the passage of a cold front is noticeable only in those areas where the prefrontal foehn touches the ground; this occurs in the Alpine valleys and in the close vicinity of the Alps. During IOPs $\mathrm{A}$ and $\mathrm{C}$ the prefrontal low-level cold air was replaced by cold air of the same temperature; therefore a temperature drop was not visible in the surface data when the front passed (Fig. 6).

The basic surface pressure distribution during foehn situations is characterized by a ridge of high pressure at the windward side of the Alps and a mesoscale lee trough. At the rear side of the approaching front the low-level flow is blocked

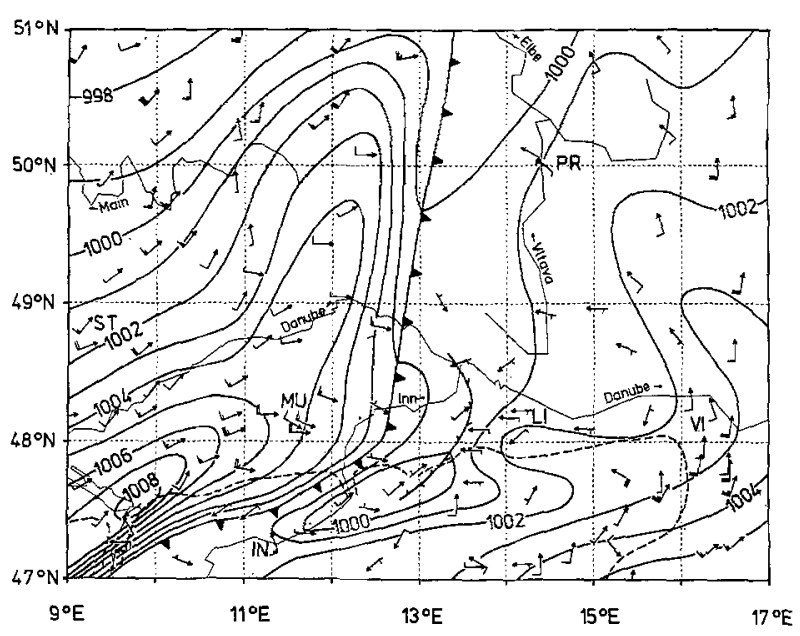

Fig. 13. Mesoscale surface analysis for 8 October 1987,12 UTC, showing the surface front line and a preceding convergence line; wind speed in knots (standard notation); pressure in $\mathrm{hPa}$; the Alpine baseline is dashed; locations: Linz (LI), Innsbruck (IN), Munich (MU), Prague (PR), Stuttgart (ST) and Vienna (VI). Taken from Hoinka et al. (1990)

at the northwestern edge of the Alps. Figure 13 shows such a typical pressure distribution as it was observed during IOP-A. North of the Alps the cross-frontal pressure difference is increased by the mesoscale pattern "high over Switzerland" and "foehn low" further to the east. This could lead to an acceleration of the front. Egger and Hoinka (1992) discussed the effects which largescale and mesoscale pressure patterns during foehn have on the progression of the front. Heimann (1992a) quantified the relative importance of both scales by systematic numerical experimentation. He identified synthetic, but realistic, parameter combinations which led to acceleration as well as deceleration of the frontal progression along the northern rim of the Alps. Routine weather forecasters, on the contrary, stressed that foehn tends to dissolve an approaching front, in particular when its southern part was trailing along the Alpine baseline (Hoinka and Smith, 1986).

Three spectacular roll clouds preceded the surface front in IOP-A. For pictures of these clouds see Hoinka and Smith (1988), Hoinka et al. (1990) and Egger and Hoinka (1992). The roll clouds were located at the leading edge of what was identified as a kind of modified gravity current interacting with the shallow, ground based stable layer (Hoinka et al., 1990). The case of 8 October 1987 is a presumably rare example of a situation 
where foehn plays an important role in the formation of roll clouds near the Alps.

The co-existence of an approaching front and the ground based cool air below prefrontal foehn is well illustrated by a time sequence of west-east cross-sections through the objectively analyzed radiosounding which were released during IOP-A (Fig. 14). The sections run along $48.5^{\circ} \mathrm{N}$ (see Fig. 1) The structure of the $\theta$-field did not deviate much from the gently sloping stratification, but lower values were imported from the west during the whole period, as is e.g. indicated by the gradual spread of the $18^{\circ} \mathrm{C}$ potential isotherm over most of the domain. The air mass marker $\theta_{e}$, however, showed a quite different structure. At 06 UTC the cool and dry postfrontal air $\left(\theta_{e}<38^{\circ} \mathrm{C}\right.$; cf. Fig. 2b) was still to the west of $7^{\circ} \mathrm{E}$, but air of lower equivalent potential temperature was situated below $2 \mathrm{~km}$ in the eastern half of the section. By 09 UTC the front had entered the section with the warm end of its gradient zone at about the $150 \mathrm{~km}$ position, while the centre of the cool pool below the foehn air lay some $200 \mathrm{~km}$ further to the east. At 12 UTC the cool pool had disappeared and the gradient zone in the $\theta_{e}$-field continued to progress further to the east.

Although it has to be noted that the horizontal positioning within the objective analysis scheme is only accurate to about $80 \mathrm{~km}$ (due to an average distance between the soundings of that order and to imperfect synchronization of the release times), the good temporal coherence of the four independent samples shows the quality of the method. Most remarkable is the development of a funnel of air with higher $\theta_{e}$-values from aloft down to the $1 \mathrm{~km}$ level. Between 06 and 09 UTC this funnel got squeezed in between the advancing cold front and the quasi-stationary cool pool. The horizontal gradients in potential temperature increased at its western and eastern side. A very similar feature was computed by a regional weather prediction model (Volkert et al., 1992).

The structure of the funnel suggests an advection from aloft; yet the change in potential temper-
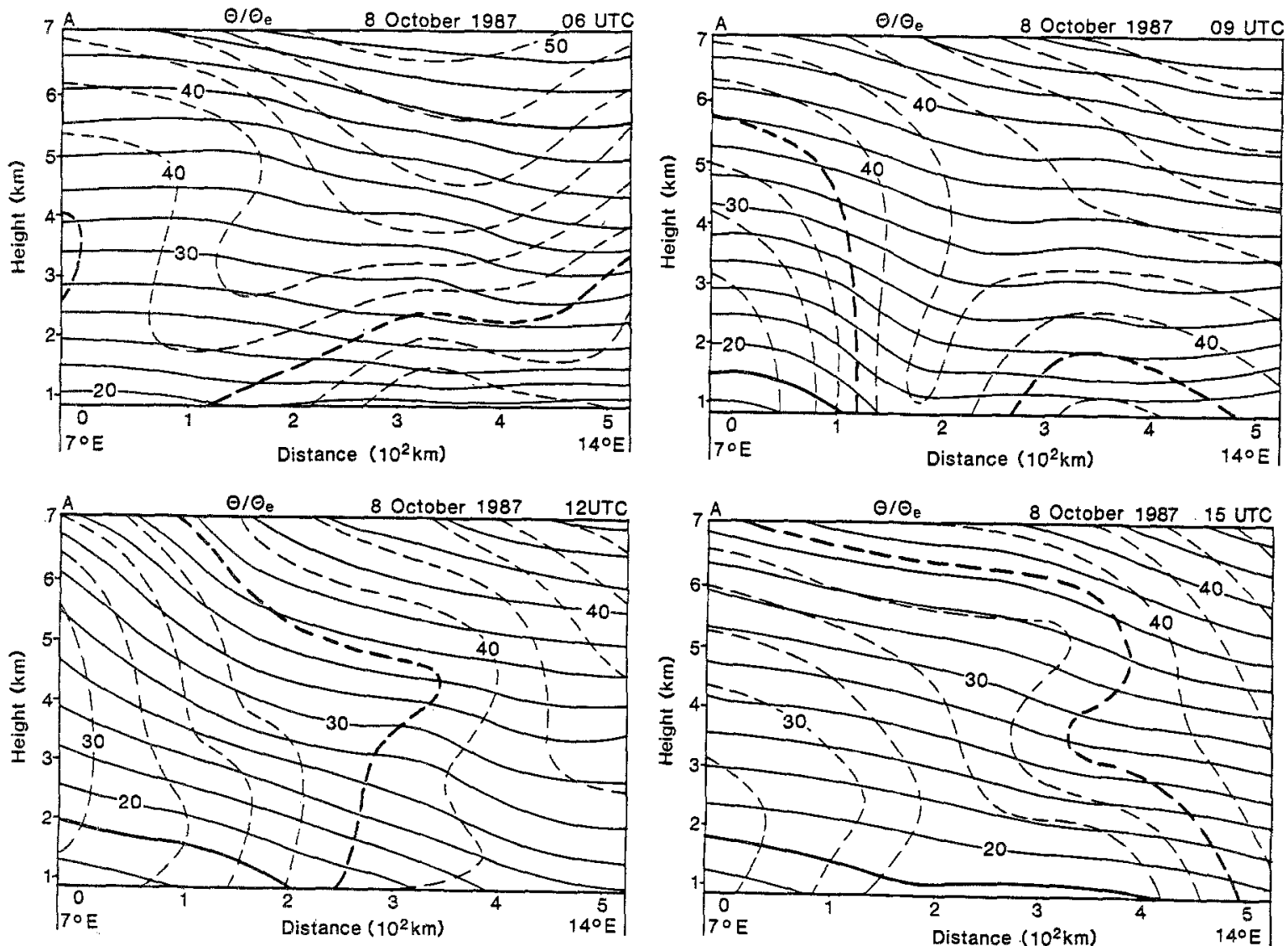

Fig. 14. Vertical cross-sections $(x, z)$ of potential temperatures (bold lines) and equivalent potential temperatures (dashed lines) on 8 October 1987 (10P-A), 06, 09, 12 and 15 UTC, derived from rawinsonde data 
ature structure would presuppose a subsidence of about $30 \mathrm{~cm} \mathrm{~s}^{-1}$ and, consequently, a strong signal in the horizontal divergence. This is not supported by the data. A second possibility of explaining the funnel is that it is due to the prefrontal conveyor belt; in fact, the flow comes from the south-west, but contains no jet-like structure. So, it is most likely that this tongue is due to an along-front advection of moist air ahead of the front from the southwest below crest height; this moist air is trailed by the northwestern edge of the Alps and is trapped north of the Alps between the cold air of the front and the warm dry air associated with the foehn. As the front propagates towards the east this air is squeezed in between the cold air of the front and the cool pool beneath the warm air of the prefrontal foehn.

Apparently the documented decoupled structures in the fields of $\theta$ and $\theta_{e}$ lead to a separation of the maximum lines of $(\partial \theta / \partial x)$ and $\left(\partial \theta_{e} / \partial x\right)$. See Heimann (1992b) for more details.

\subsection{Orographically Trapped Gravity Currents}

It is frequently the case that fronts at their leading edge are accompanied by line convection produced by cold air outflow which may have locally the character of a gravity current (Smith and Reeder, 1988). A prominent feature of a gravity current is that just behind the leading edge, the flow above a shallow friction layer is towards the leading edge in a frame of reference moving with the leading edge. Under special conditions such a current can be trapped by a vertical wall and is, thus, be forced to run along it. So, in this sub-section, we look for relevant evidence of orographically trapped gravity currents in the data of the GFE87 and related fronts.

The hourly isochrones of the surface front positions for the papal front of 3 May 1987 clearly indicate an accelerating progression of the front along the Alpine baseline (Fig. 15). Within four hours the average speed had doubled leading to the distinct bulge of the isochrones north of the Alps. Furthermore, postfrontal wind observations and model calculations revealed that an orographic jet below crest height had developed on that day (for details see Volkert et al., 1991). Inspection of the mesoscale surface front isochrones for all IOPs (Fig. 4) does not show a comparable isochrone bulge. Moreover, no indications of an orographic

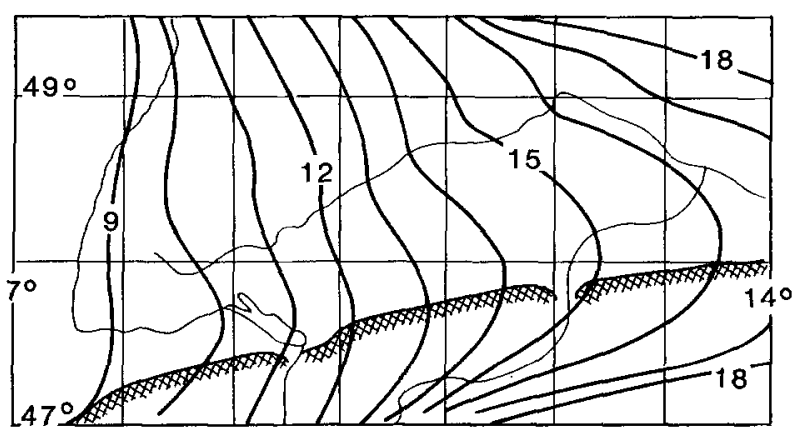

Fig. 15. Hourly isochrones of the surface front position for the "Papal Front" on 3 May 1987. The baseline of the Alps is indicated at the bottom part of the figure. Taken from Volkert et al. (1991)

jet along the Alps have been found in the data of IOPs A to D.

The situation changes somewhat when we go down in scale. As outlined in some depth by Hoinka et al. (1990), the front of IOP-A had the characteristics of an anafront in the synoptic scale. In the small scale, however, gravity current features as relative postfrontal flow towards the leading edge of the front near the ground and sudden pressure jumps have been analyzed. Taking into account also the small scale flow patterns (as deduced from Doppler radar measurements) combined with temperature information from aircraft traverses (Fig. 16) and the occurrence of roll clouds, the small scale appearance of the frontal head was classified as that of a gravity current, which had been modified by the interaction with a ground based stably stratifield layer. Such a view is strongly supported by results from numerical experiments where an initially pure gravity current was run into a stably stratified environment (Haase and Smith, 1989; Haase, 1991).

Mesoscale evidence is available from the already mentioned objective analysis of the rawinsonde network, which was operative during the experiment. Figure 17 shows the horizontal structure of the relative cross-frontal flow at the 850 and $700 \mathrm{hPa}$ levels (frontal speed $c=18 \mathrm{~m} / \mathrm{s}$ ). In both levels there is a distinct relative flow towards the front, both from its rear and from the prefrontal area. This is a characteristic feature for an ana-type cold front. Additionally we find an isolated region of positive relative flow (up to $2 \mathrm{~m} / \mathrm{s}$ ) about $50 \mathrm{~km}$ north of the alpine baseline and approximately $100 \mathrm{~km}$ ahead of the postfrontal region. This 


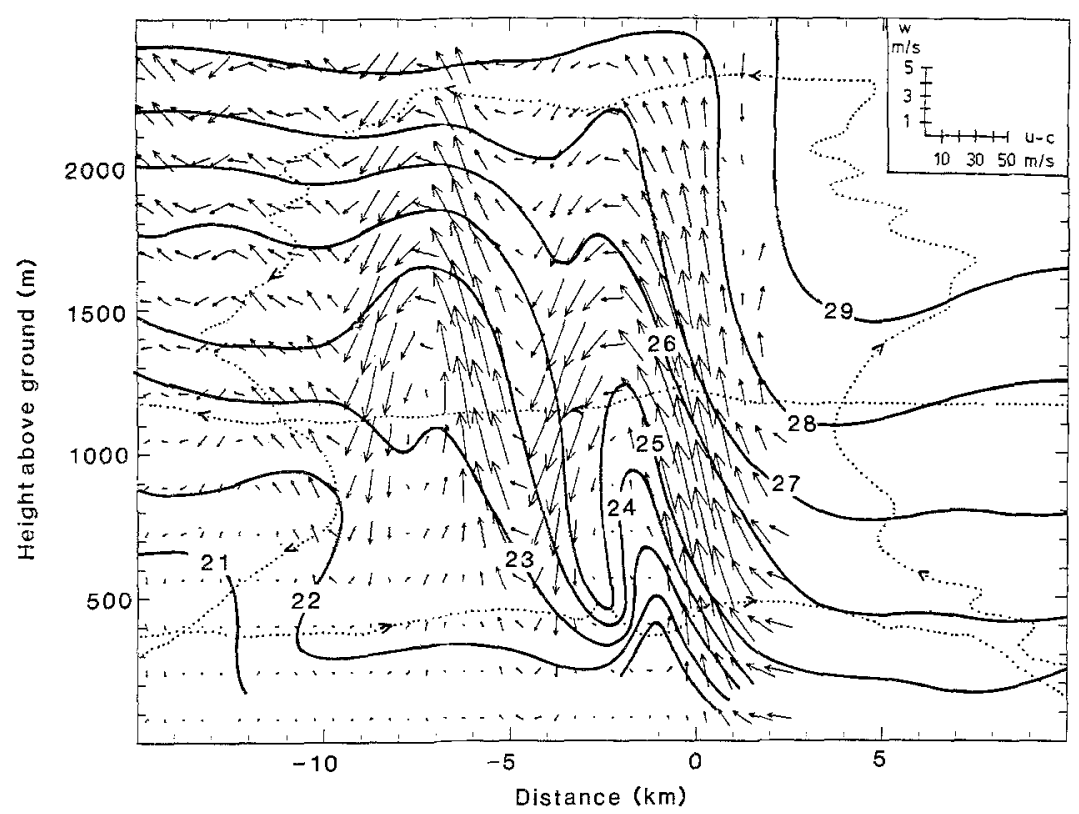

Fig. 16. Composite of airflow and potential temperature $\left({ }^{\circ} \mathrm{C}\right)$ on 8 October 1987 in a frame of reference moving with the surface front line as determined by the Doppler radar in Oberpfaffenhofen and aircraft (flight tracks dotted; Queenair in the middle; circumference flight by a powered glider). The scale of the horizontal and vertical wind is given in the top right corner. Taken from Hoinka et al. (1990) appear to be consistent with the small scale observations of a modified gravity current.

All in all, it became evident through the GFE87 that an unquestionable documentation of atmospheric gravity currents constitutes a difficult task,
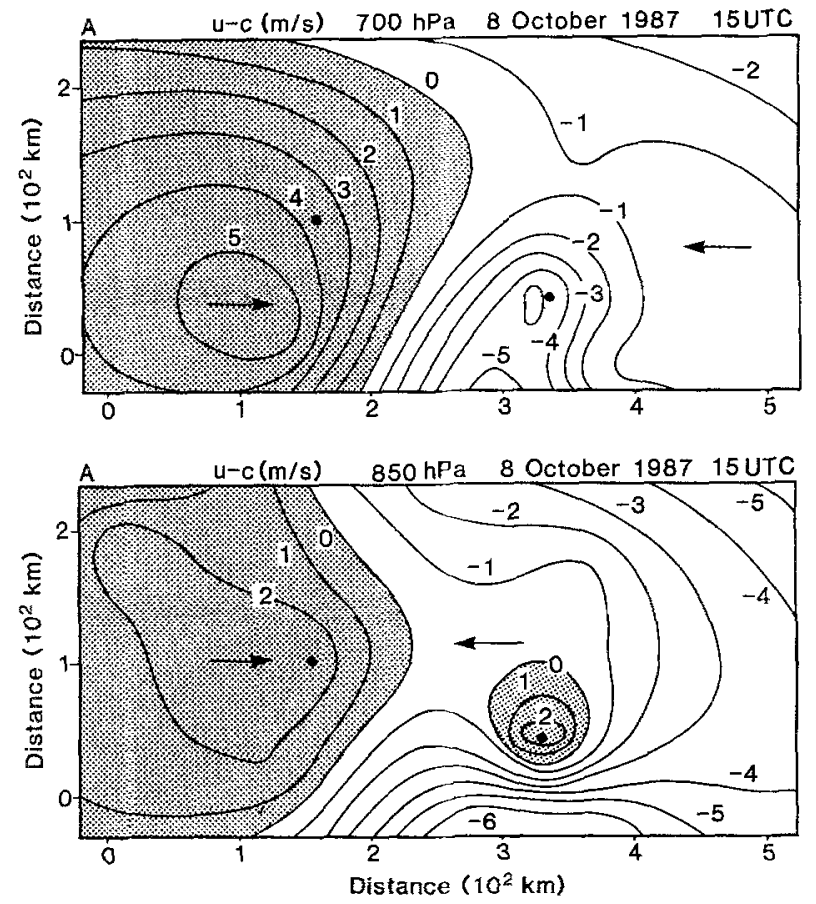

Fig. 17. Horizontal cross-sections $(x, y)$ of relative flow $\left(\mathrm{m} \mathrm{s}^{-1}\right)$ in a frame of reference moving with the front $(c=18$ $\mathrm{m} \mathrm{s}^{-1}$ ) on 8 October 1987, 15 UTC (IOP-A). The top (bottom) figure shows the $700(850) \mathrm{hPa}$ level. The dots indicate Stuttgart (left) and München and even more so for orographically trapped ones. Basically two approaches can be distinguished: Either a remote sensing instrument as a Doppler radar is available at the right time and place. During IOP-A we were lucky to observe the modified gravity current with the radar located in Oberpfaffenhofen just when it passed the site. Alternatively, a dense array of, say, microbarographs could monitor disturbances over an extended period of time and, thus, enhance the chance to detect some gravity currents, which do not seem to be frequent features at the northern rim of the Alps.

\section{4,4 Flow into Valleys}

It was v. Ficker who first stressed that the cold air behind a cold front arrives later in the Inn valley than in the Bavarian foreland. Three possibilities exist how cold air can enter a valley: from the mouth, from the head or flowing over the mountains bordering the valley. The effect mentioned by v. Ficker is related to fronts which pass along the Alps from west to east similar to the front of IOP-A; in this case the air is blocked by the mountains and is able to enter the Inn valley only from the mouth. In this sub-section we briefly summarize two studies: the first dealt with the situation in the valley of river Loisach, which extends northwards from Garmisch and intersects the Alpine baseline almost perpendicualar, while the second concentrated on the Inn valley. 
Data of IOP-A suggest that the cold air entered the Loisach valley in a way similar to a gravity current (Müller and Sladkovic, 1990). In Fig. 18 surface wind and pressure traces are shown. As soon as the front crossed the mouth of the Loisach valley the pressure difference between the foreland station (Uffing) and the valley station (Garmisch) changed from prefrontal negative to positive values. For more than an hour the pressure difference was of the order of $2 \mathrm{hPa}$, then an almost exponential decrease is observed. This behaviour is reflected in the wind field; the down-valley directed pressure gradient induce an up-valley flow from the northeast at Garmisch and an increase in wind speed of up to $7 \mathrm{~ms}^{-1}$. The flow from the foreland into the valley was not only confined to the surface layers but extended also to higher levels. Since wind measurements in the foreland do not show a northerly flow component behind the front, the northerly current was explained as an orographic effect.

Based on these observations it is reasonable to presume that the airflow within the valley was mostly driven by the pressure difference between the postfrontal cold air and the prefrontal warm air. By the time when the cold air began to penetrate into the valley, it had primarily a gravity current structure as the valley walls prevented the formation of an along-front balancing current and

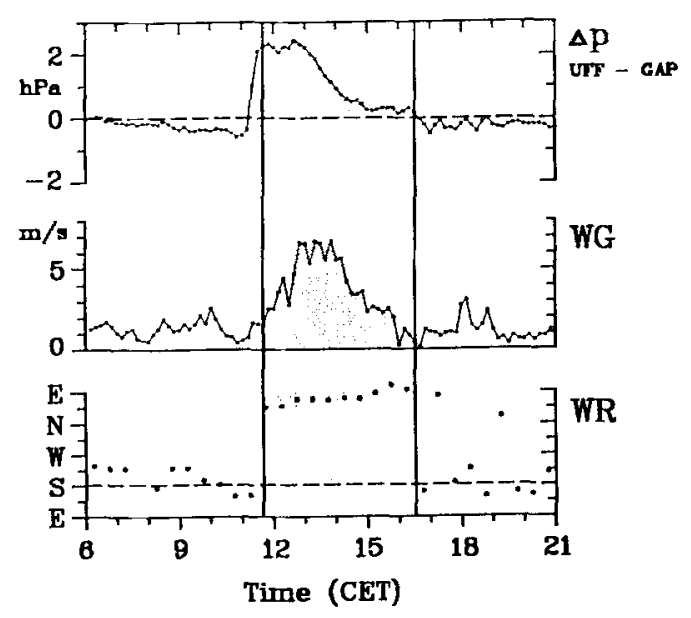

Fig. 18. Temporal evolution of pressure difference $\Delta p$ between the foreland (UFF: Uffing) and the valley (GAP: Garmisch), the wind speed at Garmisch (WG) and the wind direction at Garmisch (WR) on 8 October 1987 (IOP-A). The time is given in Central European Time $($ CET $=\mathrm{UTC}+1 \mathrm{~h})$. Taken from Müller and Sladkovic (1990) helped to decouple processes below crest height from those above.

The flow into the Inn valley during IOPs $A$ and B is analyzed by Freytag (1990). He showed that in the valley the propagation speed is reduced to $30 \%$ of the value observed over the foreland. Associated with this decrease in velocity is an increase in steepness of the front. The slope of the frontal surface with height $(\Delta z: \Delta x)$ is between 1:60 and 1:130 over the foreland, 1:7 at the mountain barrier and 1:20 in the Inn valley. The pressure jumps decreased from $2-3 \mathrm{hPa}$ over the foreland to less than $0.5 \mathrm{hPa}$ in the Inn valley (see Fig. 10).

\subsection{Modification of Precipitating Patterns}

Bjerknes and Solberg (1921) demonstrated that the formation of rain associated with a cold front near orography depends strongly on the orientation of the cold front relative to the barrier. They showed that fronts oriented southwest to northeast enhance heavy rain above the Norwegian coastal ranges, even $12 \mathrm{hrs}$ in advance, whereas fronts oriented southeast to northwest are associated with very weak precipitation. About $50 \%$ of the annual precipitation in the Alpine foreland is associated with fronts and it is known that during single events the precipitation may exceed the amount of $100 \mathrm{~mm}$ within $12 \mathrm{hrs}$ (e.g. Pike, 1988).

Directly behind the papal front a precipitation complex crossed southern Bavaria during the afternoon of 3 May 1987. It intensified while propagating along the rim of the Alps at a speed similar to that of the surface front (Fig. 15). It was analyzed from raingauge registrations that the main increase in precipitation intensity took place over a distance of $60 \mathrm{~km}$ starting from the Lake of Constance towards the east. The onset intensity developed from $9 \mathrm{~mm} / \mathrm{h}$ (Langenargen at Lake of Constance) through $45 \mathrm{~mm} / \mathrm{h}$ (Isny, $20 \mathrm{~km}$ to the west of Kempten) to $280 \mathrm{~mm} / \mathrm{h}$ (Kempten). The peak rate observed was $7 \mathrm{~mm}$ in $1.5 \mathrm{~min}$. From then onwards, the downpour moved quite uniformly and roughly parallel to the Alpine baseline with peak intensities, varying between 20 and $70 \mathrm{~mm} / \mathrm{h}$, always observed shortly after the onset of precipitation. These intensities fall into the class of intense convective storms as defined by peak intensities of more than $50 \mathrm{~mm} / \mathrm{h}$. Instead of multiple precipitation lines separated by gaps, the papal front was followed by a single downpour of about $2 \mathrm{~h}$ dura- 
tion with an areal extent of at least $300 \mathrm{~km} \times 100 \mathrm{~km}$ (Volkert et al., 1991).

During IOP-D the first observation of a narrow cold frontal rain band (or line convection) by Doppler radar near the Alps was performed. The analysis of precipitation data indicates an intensification of the frontal rainband as soon as it reached the orography. The general features associated with this rainband were similar to those observed over the northwestern United States and over England. For a detailed discussion see Hagen (1992).

Stimulated by preliminary analyses of GFE87 data Heimann (1990) performed numerical simulations to investigate the forcing effect that the Alpine orography exerts on frontal precipitation patterns. Figure 19 shows the temporal evolution of isochrones of two synthetic cold fronts ap-
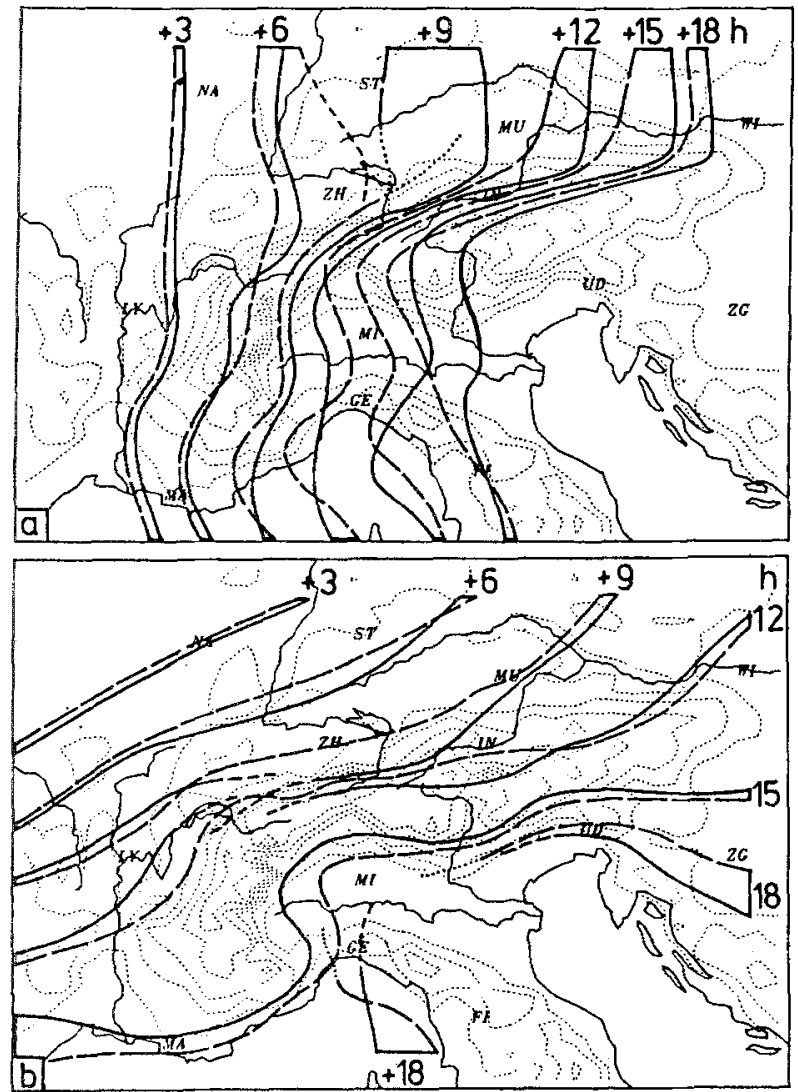

Fig. 19. Three-hourly isochrones of the surface front line for a front approaching from the west (top) and from the northwest (bottom) as simulated by a numerical model (Heimann, 1990). The front positions regarding latent heat conversions are presented by full lines, those neglecting this process are given by longly dashed lines. Uncertain or ambiguous positions are plotted with shortly dashed lines
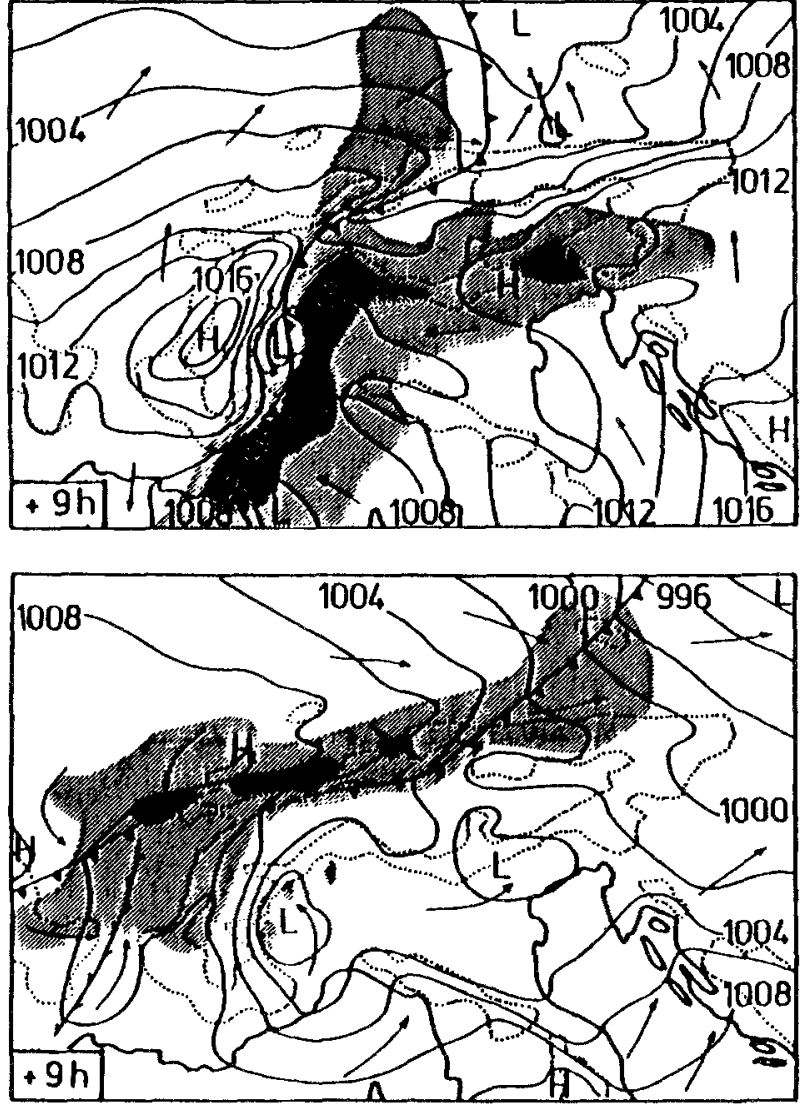

Fig. 20. Numerically simulated surface weather maps with isobars $(\mathrm{hPa})$ of pressure reduced to MSL, position of the front, convergence line, wind directions and precipitation intensity (threshold values are 0.5 and $5 \mathrm{~mm} / \mathrm{h}$ ). The dotted lines represent terrain elevations of 800 and $1600 \mathrm{~m}$ MSL. The top (bottom) figure represents the simulation of a front approaching from the west (northwest). Taken from Heimann (1990)

proaching the Alps from the west (top; similar to IOP-A) and from the northwest (bottom; similar to IOP-D). In the former case, the consideration of precipitation processes considerably enhances the speed of frontal propagation north of the Alps, whereas dry and moist calculations do not differ much in that respect for the latter case. Over and south of the Alps frontal speed does not depend much on moisture in both cases.

The reason for the differences obtained north of the Alps is due to the location of the precipitation areas relative to the front. In the case of a front approaching from the west, precipitation forms well behind the surface front line (Fig. 20, top). This leads to an enhancement of the cross-frontal temperature gradient which in turn accelerates the frontal propagation. In the case of a front ap- 
proaching from the northwest (Fig. 20, bottom), the precipitation north of the Alps forms also ahead of the surface front line due to an orographically forced lifting of the pre-frontal air as the front gets closer to the Alps. This precipitation on both sides of the front does not induce differences in the frontal speed, because the effect of the latent heat release acts on both sides of the front.

Fronts approaching the Alps from the west are significantly retarded (Fig. 3) and the prefrontal moist low-level jet, often called warm conveyer belt, is likely to be partially blocked by the Alps. This cut-off of moist air was simulated by a numerical model (Majewski, 1988), which compares simulation of IOP-A using full model Alps with runs where the Alpine orography was cut-off at the $500 \mathrm{~m}$ level. In the latter case, the frontal precipitation moved undisturbed from west to east, whereas in the case with Alps the precipitation ceased in the area of Ulm and the eastern regions received no precipitation as time progressed. This is reasonable because the low-level jet is forced to ascend at the southern side of the Alps and to descend as a relatively dry flow north of the barrier. The data analysis of IOP-D gave some hints that the prefrontal low-level jet was weakened if not partially blocked by the Alps (Hagen, 1992).

\section{On the Analysis of Fronts}

In the preceding sections we have presented a variety of frontal analyses using synoptic scale and mesoscale observations as well as numerical model output. The criteria where to analyze the front were implicitly assumed. Therefore, we discuss in this section the problem of frontal analysis, first from a more general point of view and then with special emphasis on the Alpine region and data of GFE87.

\subsection{Historical Retrospective}

It is obvious that data representing the different scales of atmospheric motions, e.g. those taken with a microbarograph or those from a satellite, give different views regarding the appearance of the same phenomenon. The recognition of the quite different appearance of a front when analyzed in the synoptic, meso, and small scale, necessitates defining what is meant by the term "front".

In a recent review of theoretical and observational studies relating to the low-level structure of cold fronts, Smith and Reeder (1988) discuss the variety of conceptual models of fronts. They point out that there is a contradiction in what is thought to be a front. Some observational studies suggest that a front is a "material surface" as in Margules' model. Others show that fronts cannot be considered to be substantial surfaces at lower levels. Other observational studies reason that some cold fronts, even nonprecipitating ones, have locally the structure of a "gravity current". Others still characterize a front as a sloping "transition zone" which separates two air masses.

In the historical retrospect it becomes clear that the appearance of the various conceptual models is strongly correlated with the development of observational and measurement facilities. By 1925 the Norwegian school had established a method for classifying air masses on the basis of their life histories. For reason of simplicity the intersection of the frontal transition zone with the surface was plotted as a line in the surface chart which led in the daily use to the idea that in the lower troposphere the front is represented by a surface of discontinuity. However, with the increase in use of aerial soundings and availability of radiosonde data it became clear that the front are more of the character of a hyperbaroclinic "transition zone" between two air masses. Later on, observations with radar, microbarographs and similar high resolution measurement systems gave indications that surface fronts may in the small scale be analogous to "gravity currents", which had been studied already at the beginning of this century.

We believe that the following contains most of the commonly known scale-dependent aspects of fronts ${ }^{2}$. A front is a three-dimensional transition zone between different synoptic-scale air masses, which is characterized by a significant change in meteorological parameters. Within this zone, inclined surfaces exist, called frontal surfaces, on which the parameters themselves are constant or on which their spatial derivatives satisfy extremal conditions. The intersections of frontal surfaces with horizontal planes are called frontal lines and the intersections with the earth's surface are referred

\footnotetext{
2 This attempt to summarize the various aspects of the term "front" stems from a discussion with Reinhold Steinacker (Universität Innsbruck), Veronica Zwatz-Meise and Christian Kress (both Zentralanstalt für Meteorologie und Geodynamik, Wien) and Dieter Heimann (DLR)
} 
to as surface front lines. In synoptic scale analyses the different frontal surfaces (lines) may well result in a single frontal surface (line) due to the limited resolution of the available data.

\subsection{Difficulties due to the Alpine Orography}

Steinacker (1982) exemplified that a frontal analysis over the Alpine region, which takes into account all available surface and mountain stations, is feasible, but only with an extensive amount of work. Moreover, this type of analysis is neither objective nor routinely applicable. Therefore, on occasions there can be considerable uncertainty about the correctness of a surface analysis. An illustrative example of the difficulty of analyzing the surface front line above the Alps during IOP-A is given in Fig. 21 where analyses of three different analysts are compared. In both, the synoptic-scale and the meso-scale area the analyses agree well over flat terrain but differ considerably over the Alpine region.

For routine weather forecasting the "thermal front parameter" (TFP) can be used for objectively analyzing fronts from model output data. This approach is based on upper air data (Renard and Clarke, 1965)

$\mathrm{TFP}=-\nabla_{H}\left|\nabla_{H} \psi\right| \cdot \frac{\nabla_{H} \psi}{\left|\nabla_{H} \psi\right|}$,

where $\nabla_{H}$ is the nabla-operator evaluated at constant height; the variable $\psi$ could be the potential temperature $\theta$, the equivalent potential temperature $\theta_{e}$ or the thickness between two level, e.g., $850 \mathrm{hPa}$ and $500 \mathrm{hPa}$. According to this definition, the maximum lines of the TFP identify fronts as the warm air boundary of high-gradient zones.

During the last decades satellite images have been regarded as helpful tools for analysing fronts (cf. Kletter, 1966, for an early Alpine example). However, the determination of surface front lines by interpreting satellite data is controversially discussed (Kurz, 1986; Zwatz-Meise, 1989). The frontal movement in the Alpine area can be masked by the diurnal variation in cloudiness, so that at times the front appears to have dissolved and later it seems to have jumped ahead. Figure 22 gives an intercompar on for IOP-A of a surface front line analysis based on conventional data with the TFP and with structures extracted from satellite images. It shows that the interrelation between the three
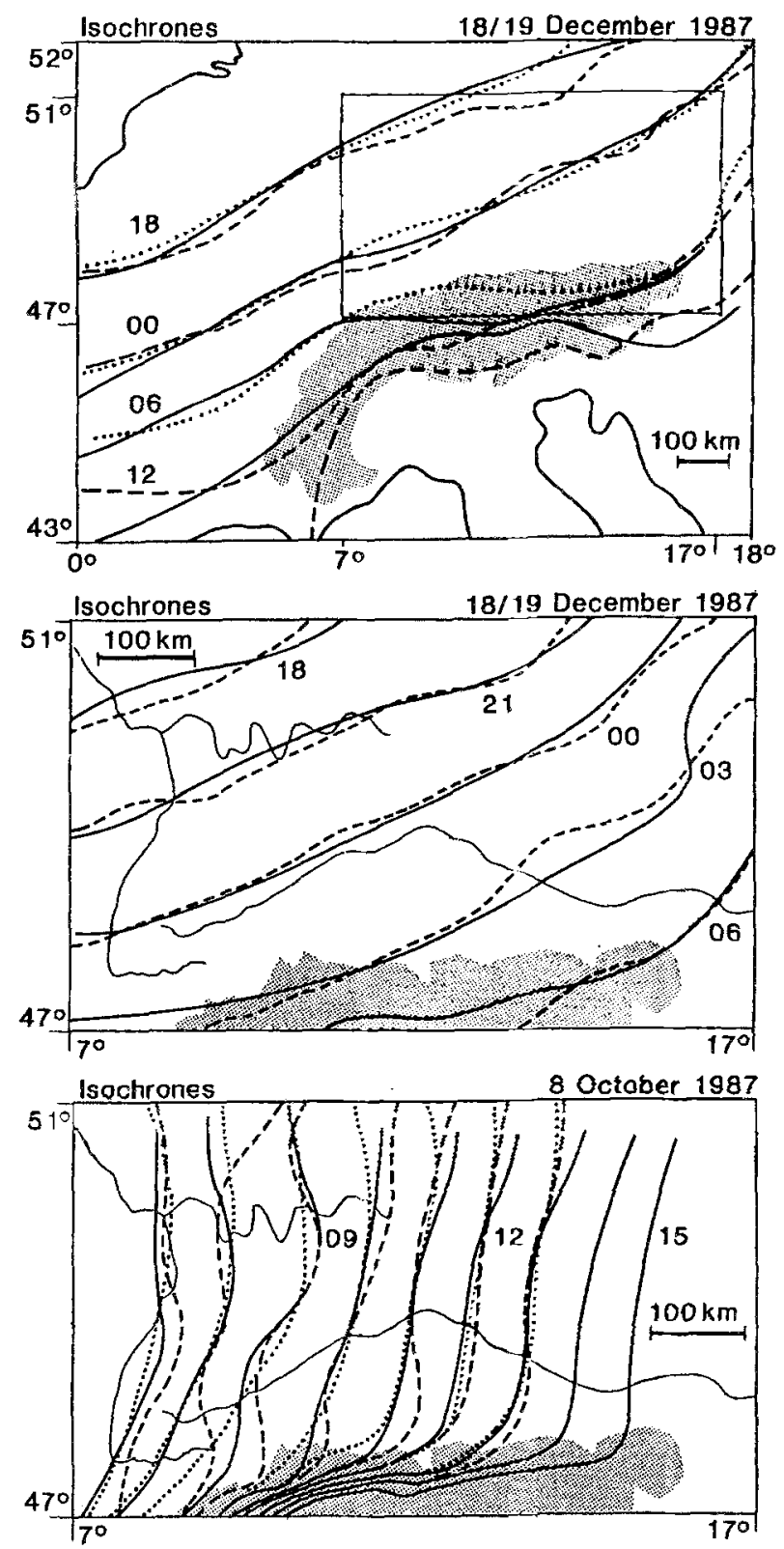

Fig. 21. Subjective analysis of the isochrones on $18 / 19$ December 1987 (IOP-D) and on 8 October 1987 (IOP-A) by three different analysts: D. Heimann (DLR, Oberpfaffenhofen; full lines); R. Steinacker (Universität Innsbruck; dashed lines); M. Kurz (Deutscher Wetterdienst, Offenbach; dotted lines). The enlarged area shown in the centre and bottom figures is indicated in the top figure

approaches is reduced as soon as the front crosses the Alps. The TFP gives good results above level terrain, but is less satisfactory above orography. This is due to the fact that conventional analyses with radiosonde and surface data usually show a decoupling of the upper level and low level part of the fronts above the Alps; the upper level part 

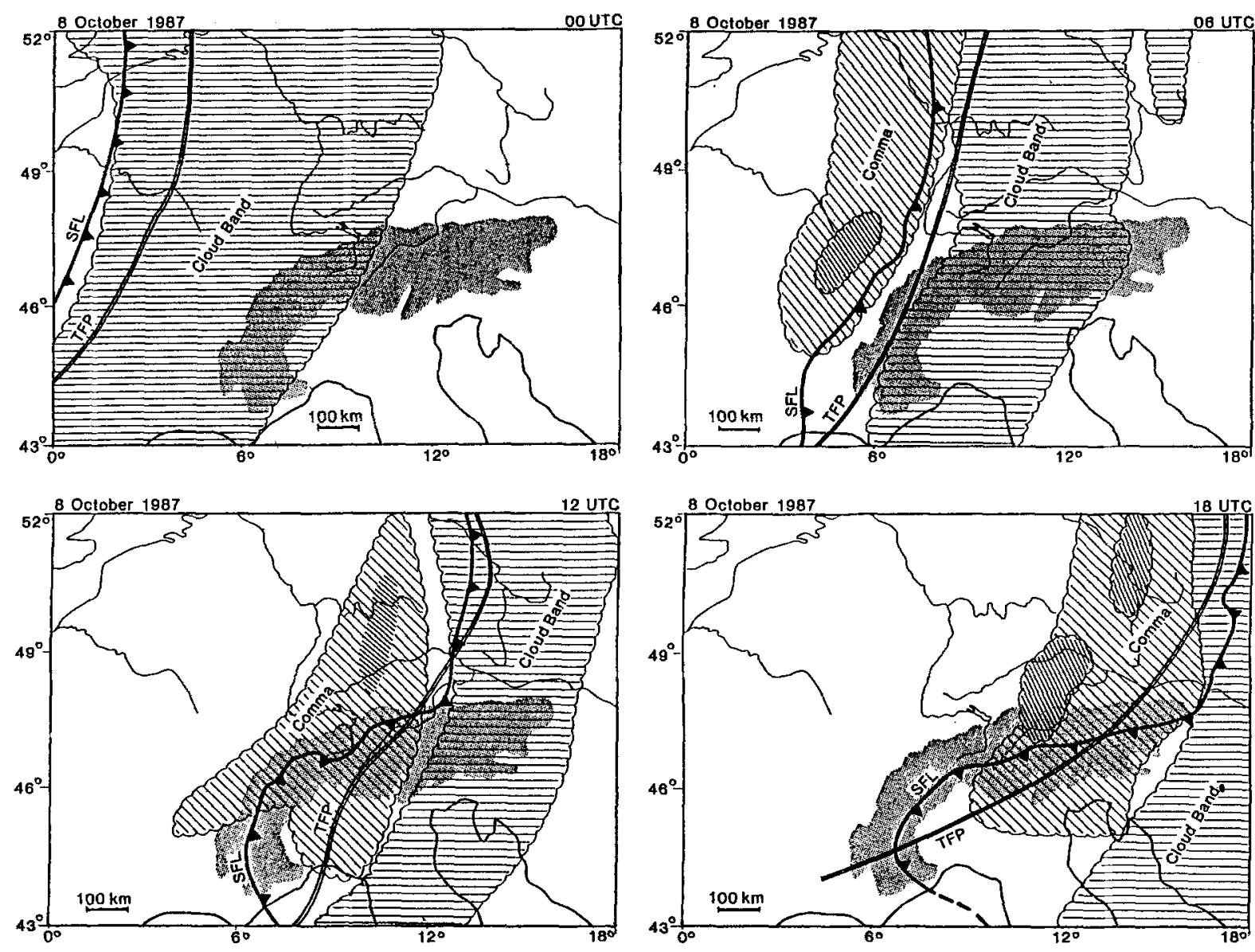

Fig. 22, Intercomparison of frontal analysis for IOP-A, 8 October $1987(00,06,12,18$ UTC). The surface front line with triangles was provided by R. Steinacker; the double lines indicate the position of the maximum lines of the TFP by V. Zwatz-Meise; the cloud distribution was taken from the corresponding METEOSAT pictures by V. Zwatz-Meise. The patches in the comma cloud indicate areas with elevated (i.e. very bright) cloud tops

seems to be little influenced by the Alps, whereas at low levels a strong retardation becomes evident. This means that the Alps favourably induce frontal surfaces which are inclined forwards.

It has to be admitted that above complex terrain the method to derive the surface front line from tropospheric data or from upper level clouds is at best inadequate and at worst misleading. This is particularly true for meso scale areas as shown for IOP-A. It is again worth mentioning that the difficulty of frontal analysis above complex terrain is well known to weather observers and forecasters in the area (Hoinka and Smith, 1986). To focus on it was one of the scientific goals of the GFE87. An improved method using a modified TFP has been worked out by Steinacker (1991) recently. Yet, the necessity of finding better ways to analyze fronts in the Alpine area remains.

\section{Concluding Remarks}

The analysis of the data collected during the GFE87 in combination with the results obtained from numerical simulations allowed to answer some of the questions and hypotheses raised during the planning phase of the experiment:

- Synoptic scale analysis shows that in the vicinity of the Alps fronts are intensified; meso scale data analysis and small scale data such as temperature and pressure registrations indicate that pressure jumps and temperature drops associated with a cold front are intensified close to the orography. Frontolytic effects have not been found in the data of the GFE87.

- The orography appears to induce a splitting into a dynamical effective front line which is correlated to the maximum gradients in $\theta$ and a 
thermodynamical effective air mass boundary represented by the maximum gradients in $\theta_{e}$.

- Simulations and observations confirm that a cold front can be intensified by prefrontal foehn which is apparent in an increase in speed of propagation and in an increase in cross-frontal gradients. Up to now the effect that foehn can act frontogenetic was not recognised as a significant process by weather forecasters. The pressure distribution north of the Alps with a meso scale ridge of high pressure due to blocking at the northwestern edges of the Alps and a mesoscale prefrontal trough due to foehn results in a orographically forced stronger pressure gradient which may lead to an increase in frontal speed. Cases when foehn dissolved a cold front were not observed during GFE87.

Orographically trapped gravity currents did not occur during the GFE87. However, a modified gravity current was observed during the experimental phase which was indirectly influenced by the orography. At the leading edge of the front a gravity current developed probably as outflow from a precipitation area and propagated into the shallow stable air based at the ground north of the Alps which is commonly present during south foehn; the gravity current was modified in this shallow layer of cold air.

- The data show that the flow into the valleys carries features of a gravity current. The crossfrontal gradients seem to weaken as soon as the front enters the valley and the slope of the frontal interface steepens.

It was the first time that a narrow cold frontal rainband was intensely observed close to the Alps. The data indicate modifications in precipitation rates associated with the orography. Precipitation associated with fronts appears to intensify the front and its speed of propagation as soon as the precipitation is at the rear side of the front whereas in case of pre- and postfrontal precipitation the front itself is not intensified.

- Numerical simulations and data analysis suggest that the moist prefrontal low-level jet, the conveyor belt, is partially blocked by the Alps.

Stimulated by the preparation of the experiment detailed interpretations of several fronts, which were observed during recent years, were performed showing the frontogenetic impact of the Alps. As a general result of this, it became obvious that a thoroughful analysis and interpretation of only routine data results in valuable insights. It is also concluded that a series of "routine-data case-studies" could help to determine the variability of frontal progression along the Alps in order to provide guidance when assessing the significance of single events, in particular those sampled during special observing programmes.

The analysis of observational data and the numerical simulations triggered new questions. It is often observed that in the prefrontal area a convergence line is generated north of the Alps. It is suggestive that these lines are an effect of the orographic impact. Sometimes strong hailstorms develop in association with these line causing heavy damage in eastern Bavaria and western Austria near Salzburg (Hoinka, 1991).

Of course, there were some shortcomings. During the planning phase of the experiment there was a good hope that the temporal coincidence between the GFE87 and FRONTS87 could offer the unique chance of probing the same front over the sea and over central Europe influenced by the Alps. The hope was that an intercomparison of both analyses eventually gives a clear picture of the orographic impact. Unfortunately, only one event was observed by both experimental groups; it was our IOP-B and their IOP2; the analysis of both IOPs is on the way.

Recalling the central scientific objectives of the experiment (see Introduction) it is evident that the first goal, documenting several frontal events as they crossed central Europe, has been achieved; the determination of the orographic modification and the orographic impact on these fronts is presently under discussion; and finally the explanation of the physical mechanisms is far from being sufficiently achieved (see Egger and Hoinka, 1992). This can be pursued by a more thorough exploitation of the entire data base. Viewing the Front Experiment 1987 in retrospect one can certainly state, that as a field project, it was as successful as any of the international projects. Furthermore it has to be emphasized that the DFG project "Fronts and Orography" including the GFE87 had a very stimulating effect on the scientific community's interest in the topic of fronts under orographic influence.

\section{Acknowledgements}

We wish to record our thanks to all the colleagues who participated in the German Front Experiment 1987. In particular, 
we thank the German Weather Services for the supply of data including the additional rawinsonde soundings, which were funded by a grant from the German Science Foundation (DFG) under the title 'fronts and orography'. M. Pedder (Reading University) and S. Clough (UK Meteorological Office) made available software for objectively diagnosing and conveniently displaying the data shown in Figs. 12 (bottom), 14 and 17. Their generous support is gratefully acknowledged. G. Jacob gave valuable assistance in finalizing most of the figures.

\section{References}

Baldwin, D. G., Hsie, E.-Y., Anthes, R. A., 1984: Diagnostic studies of a two-dimensional simulation of frontogenesis in a moist atmosphere. J. Atmos. Sci., 41, 2686-2700.

Bjerknes, V., 1919: Veirforutsigelse: Foredrag ved Geofysikermotet i Goteborg, 28 august 1918. Naturen 43 (1919) p. 7. (Referenced in R. M. Friedman: Appropriating the weather. Cornell University Press, Ithaca 1989).

Bjerknes, J., Solberg, H., 1921: Meteorological conditions for the formation of rain. Geophys. Publ, 2, 1-69.

Blumen, W., 1992: Propagation and frontogenesis versus frontolysis over orography. Meteorol. Atmos. Phys., 48, $37-50$.

Clough, S. A., 1987: The mesoscale frontal dynamics project. Meteor. Magazine, 116, 32--42.

Durand-Gréville, M. E., 1892: Les grains et les orages. Bureau central Météorologiques de France. Annales de 1892.

Egger, J., Hoinka, K. P., 1992: Fronts and orography. Meteorol. Atmos. Phys., 48, 3-36.

v. Ficker, H., 1926: Maskierte Kälteeinbrüche. Meteorol. Zeitschr., 43, 186-188.

Freytag, C., 1990: Modification of the structure of cold fronts over the foreland and in a mountain valley. Meteorol. Atmos. Phys., 43, 69-76.

Garratt, J. R., Physick, W. L., Smith, R. K., Troup, A. J., 1985: The Australian summertime cool change. Part II: Mesoscale aspects. Mon. Wea. Rev., 113, 202-223.

Haase, S., 1991: Numerical simulation of the bore-like cold front of 8 October 1987. Tellus, 43A, 97-105.

Haase, S., Smith, R. K., 1989: The numerical simulation of atmospheric gravity currents. Part II. Environments with stable layers. Geophys. Astrophys. Fluid Dyn., 46, 35-51.

Hagen, M., 1992: On the appearance of a cold front with a narrow rainband in the vicinity of the Alps. Meteorol. Atmos. Phys, 48, 231-248.

Hartjenstein, G., Egger, J., 1990: Frontogenesis near steep orography. Tellus, 42A, 259-269.

Heimann, D., 1988: The "Papal Front" of 3 May 1987: Modelling of orographic and diabatic effects. Beitr. Phys. Atmos., 61, 330-343.

Heimann, D., 1990: Three-dimensional modeling of synthetic cold fronts approaching the Alps. Meteorol. Atmos. Phys., 42, 197-219.

Heimann, D., 1992a: Three-dimensional modeling of synthetic cold fronts interacting with northern Alpine foehn. Meteorol. Atmos. Phys., 48, 139-163.

Heimann, D., 1992b: Potential and equivalent-potential temperature patterns at cold fronts with pre-frontal Alpine foehn. Meteorol. Atmos. Phys., 48, 165-171.
Heimann, D., Volkert, H., 1988: The "Papal Front" of 3 May 1987 - mesoscale analysis of routine data. Beitr. Phys. Atmos., 61, 62-68.

Hoinka, K. P., 1985: On fronts in central Europe. Beitr. Phys. Atmos., 58, 560-571.

Hoinka, K. P., 1986: On the diagnosis of a cold front observed during ALPEX. In: Kuettner, J. (ed.) Scientific results of the Alpine Experiment, GARP Publ. Series No. $27,445-453$.

Hoinka, K. P., 1991: Mesoscale observations of a cold front associated with a prefrontal hailstorm. In: Schumann, U., Hoinka, K. P. (eds.) Contributions to Atmospheric Physics, in honour of Dr. Manfred Reinhardt to his 65 th Birthday. Research report, DLR-FB 91-30, 87-97.

Hoinka, K. P., Rösler, F., 1987: The surface layer on the leeside of the Alps during foehn. Meteorol. Atmos. Phys., 37, 245-258.

Hoinka, K. P., Smith, R. K., 1986: Ein Fragebogen zu Kaltfronten an den Alpen/A questionnaire on cold fronts in alpine regions. Research report, DFVLR Mitt. 86-02, $78 \mathrm{pp}$.

Hoinka, K. P., Smith, R. K., 1988: A dry cold front over southern Bavaria. Weather, 43, 255-261.

Hoinka, K. P., Volkert, H., 1987a: Das deutsche Front Experiment 1987: Experimentplan. Research report, DFVLR-Mitt. 87-24, 51 pp.

Hoinka, K. P., Volkert, H., 1987b: The German Front Experiment 1987. Bull. Amer. Meteor. Soc., 68, 1424-1427.

Hoinka, K. P., Volkert, H., Heimann, D., 1988: The German Front Experiment 1987: Observations and preliminary results. Research report, DFVLR-FB 88-21, 133 pp.

Hoinka, K. P., Hagen, M., Volkert, H., Heimann, D., 1990: On the influence of the Alps on a cold front. Tellus, 42A, 140-164.

Keyser, D., Reeder, M. J., Reed, R. J., 1988: A generalization of Pettersens frontogenesis function and its relation to the forcing of vertical motion. Mon. Wea. Rev., 116, 762-780.

Kletter, L, 1966: Die Alpen im polaren Kaltluftstrom, beobachtet mit TIROS IV. Arch. Met. Geoph. Biokl., A15, 32-45.

Kurz, M., 1986: Zur Interpretation von Satellitenbildern bei der synoptischen Analyse und Diagnose. Meteorol. Rdsch., 39, 145-151.

Kurz, M., 1989: Zur Analyse und Diagnose der ersten beiden Fronten des Frontenexperiments der Deutschen Forschungsgemeinschaft (DFG). Meteorol. Rdsch., 41, $147-160$.

Kurz, M., 1990: The influence of the Alps on structure and behaviour of cold fronts over southern Germany. Meteorol. Atmos. Phys., 43, 61-68.

Majewski, D., 1988: Die Front vom 8.10 .1987 simuliert mit dem Europa-Modell des Deutschen Wetterdienstes. Interner Bericht Nr. 20, Deutscher Wetterdienst, Offenbach.

Miller, J. E., 1948: On the concept of frontogenesis. J. Meteor, 5, 169-171.

Müller, H., Sladkovic, R., 1990: Case studies of frontal passages in a mountain valley with direct access to the Bavarian pre-alpine region. Results from the German front experiment 1987. Meteorol. Atmos. Phys., 43, 77-87.

Ogura, Y., Portis, D., 1982: Structure of the cold front observed in SESAME-AVE III and its comparison with 
the Hoskins-Bretherton frontogenesis model. J. Atmos. Sci., 39, 2773-2792.

Pike, W. S., 1988: 54-Hours of continuous post-frontal precipitation north of the Alpine mountain barrier, 22-25 August 1975. Weather, 43, 246-254.

Renard, R. J., Clarke, L. C., 1965: Experiments in numerical objective frontal analysis. Mon. Wea. Rev., 93, 547-556.

Smith, R. K., Reeder, M. J., 1988: On the movement and low-level structure of cold fronts. Mon. Wea. Rev., 116, 1927-1944.

Smith, R. K., Ridely, R. N., Page, M. A., Steiner, J. T., Sturman, A. P., 1991: Southerly changes on the east coast of New Zealand. Mon. Wea. Rev., 119, 1259-282.

Steinacker, R., 1982: The first ALPEX-SOP cold front on March 2, 1982. ALPEX Preliminary Scientific Results, WMO Geneva. GARP-ALPEX, 7, 87-96.

Steinacker, R., 1991: Zur objektiven Bestimmung von Frontlinien. In: Schumann, U., Hoinka, K. P. (eds.) Contributions to Atmospheric Physics, in honour of Dr. Manfred Reinhardt to his 65th Birthday. Research report, DLR-FB 91-30, 151-159.
Thorpe, A. J., Clough, S. A., 1991: Mesoscale dynamics of cold fronts: Structures described by dropsoundings in Fronts87. Quart. J. Roy. Meteor. Soc., 117, 903-941.

Thorpe, A. J., Volkert, H., Heimann, D., 1992: Mesoscale dynamics of flow along the Alps. Quart. J. Roy. Meteor. Soc. (submitted).

Volkert, H., Weickmann, L., Tafferner, A., 1991: The "Papal Front" of 3 May 1987 - a remarkable example of frontogenesis near the Alps. Quart. J. Roy. Meteor. Soc., 117, $125-150$.

Volkert, H., Kurz, M., Majewski, D., Prenosil, T., Tafferener, A., 1992: The front of 8 October 1987: Predictions of three mesoscale models. Meteorol. Atmos. Phys., 48, 179-191.

Zwatz-Meise, V., 1989: Vom Satelliten beobachtet. Beispiel einer nicht alltäglichen Frontogenese: 12.-13.11.87. Wetter und Leben, 40, 122-128.

Authors' address: Dr. Klaus-Peter Hoinka and Dr. Hans Volkert, DLR, Institut für Physik der Atmosphäre, D-W8031 Oberpfaffenhofen, Federal Republic of Germany. 